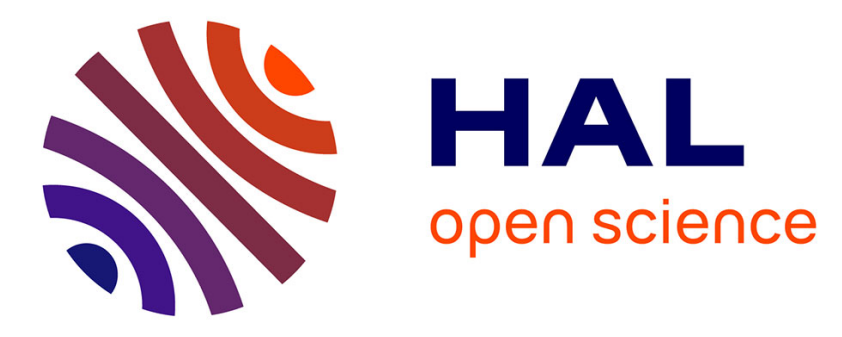

\title{
Accuracy of ground surface broadband shortwave radiation monitoring
}

Laurent Vuilleumier, Mathias Hauser, Christian Félix, Franck Vignola, Philippe Blanc, Andreas Kazantzidis, Bertrand Calpini

\section{To cite this version:}

Laurent Vuilleumier, Mathias Hauser, Christian Félix, Franck Vignola, Philippe Blanc, et al.. Accuracy of ground surface broadband shortwave radiation monitoring. Journal of Geophysical Research: Atmospheres, 2014, 119, pp.13838-13860. 10.1002/2014JD022335 . hal-01112611

\section{HAL Id: hal-01112611}

https://hal-mines-paristech.archives-ouvertes.fr/hal-01112611

Submitted on 3 Feb 2015

HAL is a multi-disciplinary open access archive for the deposit and dissemination of scientific research documents, whether they are published or not. The documents may come from teaching and research institutions in France or abroad, or from public or private research centers.
L'archive ouverte pluridisciplinaire HAL, est destinée au dépôt et à la diffusion de documents scientifiques de niveau recherche, publiés ou non, émanant des établissements d'enseignement et de recherche français ou étrangers, des laboratoires publics ou privés. 


\section{Journal of Geophysical Research: Atmospheres}

\section{RESEARCH ARTICLE \\ 10.1002/2014JD022335 \\ Accuracy of ground surface broadband shortwave radiation monitoring}

Key Points:

- The uncertainty of ground surface shortwave radiation monitoring is determined

- Realistic operating conditions using best available technology are considered

- The most stringent BSRN accuracy target may not be currently achievable

Correspondence to:

L. Vuilleumier,

laurent.vuilleumier@meteoswiss.ch

\section{Citation:}

Vuilleumier, L., M. Hauser, C. Félix, F. Vignola, P. Blanc, A. Kazantzidis, and B. Calpini (2014), Accuracy of ground surface broadband shortwave radiation monitoring, J. Geophys. Res. Atmos., 119, 13,838-13,860, doi:10.1002/ $2014 J D 022335$.

Received 19 JUL 2014 Accepted 7 NOV 2014 Accepted article online 11 NOV 2014 Published online 16 DEC 2014

\author{
L. Vuilleumier ${ }^{1}$, M. Hauser ${ }^{1}$, C. Félix ${ }^{1}$, F. Vignola ${ }^{2}$, P. Blanc ${ }^{3}$, A. Kazantzidis ${ }^{4}$, and B. Calpini ${ }^{1}$ \\ ${ }^{1}$ Federal Office of Meteorology and Climatology MeteoSwiss, Payerne, Switzerland, ${ }^{2}$ Department of Physics, University of \\ Oregon, Eugene, Oregon, USA, ${ }^{3}$ MINES ParisTech, PSL Research University, O.I.E. - Centre Observation, Impacts, Energy - \\ Sophia, Antipolis, France, ${ }^{4}$ Laboratory of Atmospheric Physics, Physics Department, University of Patras, Patras, Greece
}

Abstract The uncertainty of broadband shortwave radiation monitoring is determined for direct, diffuse, and global irradiance for measurements obtained at the Payerne (Switzerland) station of the Baseline Surface Radiation Network (BSRN). The uncertainty estimates include sources that reflect realistic long-term operation conditions. The uncertainties are derived using the methodology specified by the "Guide to the expression of uncertainty in measurement." The differences between redundant determinations of direct, diffuse, and global irradiance are analyzed and are shown to be compatible with the uncertainties. In addition, the signatures of some uncertainty sources are sought within the error statistics to find out if corrections can be applied and what their magnitude is. The global and diffuse irradiance uncertainties range from $1.8 \%$ to $2.4 \%$ without correction and are less than $1.8 \%$ with corrections. These uncertainties are close to or satisfy the BSRN targets for large signals (global: $1000 \mathrm{~W} \mathrm{~m}^{-2}$, diffuse: $500 \mathrm{~W} \mathrm{~m}^{-2}$ ). For small signals $\left(50 \mathrm{~W} \mathrm{~m}^{-2}\right)$, the targets are not achieved, mainly as a result of uncertainties associated with the data acquisition electronics (DAQ). The direct irradiance uncertainty is $\sim 1.5 \%$, 3 times larger than the BSRN uncertainty target. An accuracy gain can also be achieved at the DAQ level, but even without considering the DAQ uncertainty, the target is exceeded by a factor of about 2 . The direct irradiance uncertainty remains $\sim 1 \%$ even using an absolute cavity radiometer as transfer standard for correcting the pyrheliometer sensitivity. Thus, the direct irradiance accuracy target of $0.5 \%$ is probably not achievable with the best commercially available technology.

\section{Introduction}

Accurate determination of radiation fluxes at the Earth surface is the key to many atmospheric studies, particularly for studies related to climate change or the surface energy budget. The changes and forcings that are investigated are often of the same order as the measurement accuracy. For instance, long-term (decadal) changes in solar radiation at the Earth surface were characterized by a period of dimming (1950-1980) followed by a partial recovery (brightening, from 1980 to 2000), which continued beyond 2000 in certain regions [Wild, 2012, and references therein]. The decline in surface solar radiation during the dimming period is estimated to range from 3 to $9 \mathrm{~W} \mathrm{~m}^{-2}$, or $2 \%$ to $6 \%$ over 30 years. The subsequent solar radiation increase during the recovery is of similar amplitude or a little bit lower. These changes are of the order of 1-2\% per decade at most, and the instrumental uncertainty becomes a significant issue. It is the concordance of multiple independent studies using data sets covering different regions of the globe using specific quality analysis, such as the one proposed by Gilgen et al. [1998] or Dutton et al. [2006], that allows confidence in the detection of such decadal changes. It should be noted that the relative precision or reproducibility is more important than absolute accuracy when studying changes or trends, although this mostly relates to local changes determined with a stable measurement technology. For long-term studies, this issue is complex. Errors that are considered as biases and would cancel when studying changes typically include those linked to references used in the calibration process, e.g., the World Standard Group (WSG), or errors consistently of the same sign such as thermal offsets (section 2.3.1). But long-term studies include measurements made with different types of sensors that may have been calibrated with different methods or with thermal characteristics that differ. Thus, determining which errors are truly systematic should be done with extreme caution for such studies.

Because of the demand for high-accuracy reference data resulting from trend analysis and other needs, surface radiation monitoring networks with strict measurement guidelines ensuring high-quality data of known accuracy were initiated in the beginning of the 1990s. The Baseline Surface Radiation Network (BSRN) 
[Ohmura et al., 1998] and the U.S. Atmospheric Radiation Measurement program (ARM) [Peppler et al., 2008] are to date the networks monitoring surface radiation with the most rigorous operational procedures. The accuracy targets for BSRN SW irradiance measurements are $0.5 \%$ for direct normal and $2 \%$ for global or diffuse irradiance [McArthur, 2005]. Beyond their use in climate change studies, data from these networks provide a basis for homogenizing data records from multiple satellite platforms, a reference for other radiation monitoring networks, and an observational foundation for the improvement of radiative transfer models. Confidence in the measurement accuracy of these reference networks is crucial for all these fields.

Such accuracy targets are expected to be achievable when applying the BSRN guidelines and operation procedures; although there have been relatively few studies demonstrating that these targets are actually reached at the BSRN stations operational worldwide. Measurement uncertainty has been described both for standards [Fröhlich, 1977; Reda, 1996] and for more common radiation monitoring instruments [Reda, 2011], considering near-ideal conditions. In other cases, the agreement between instruments has been established in intercomparisons [Michalsky et al., 2003, 2011]. In these cases the operation conditions are carefully controlled resulting in situations fully compliant with the BSRN guidelines, i.e., conditions that can be considered almost ideal.

Dutton and Long [2012] recently reported an assessment of surface radiation uncertainty, including comparisons of agreement between collocated instruments. The expanded uncertainties reported are typically $\sim 15 \mathrm{~W} \mathrm{~m}^{-2}$ for the direct normal and diffuse horizontal irradiance (DNI and DfHI, respectively) and 20-25 W m ${ }^{-2}$ for global horizontal irradiance (GHI). In their report, Dutton and Long distinguish uncertainty estimations obtained by "mathematically combining individual error contributions from all known sources (sometimes called formal error analysis), comparisons to reference instruments for which a detailed uncertainty has been estimated by the formal method, and by an evaluation of the spread of independent collocated simultaneous observations that provides a realistic uncertainty range that includes unanticipated and undetected operational errors." In this study, we use all three methodologies.

Radiation monitoring has been ongoing at some BSRN and ARM stations for over 20 years. Ensuring full compliance with BSRN operational procedures over such a long period is challenging. At some BSRN stations, including Payerne, the daily maintenance requirement was relaxed to exclude weekends and holidays for reducing costs. Such relaxed requirements increase the risk of measurement errors due to external perturbations, typically soiling. But even with a strict observance of BSRN guidelines, perturbations due to rain, snow, frost, or soiling cannot be avoided. Erroneous measurements are usually rejected by quality control (QC) [e.g., Long and Shi, 2008]. QC identifies large measurement errors, and the related problems are quickly resolved. But more subtle problems resulting in small errors are usually identified by statistical quality analysis $(\mathrm{QA})$, which sometimes occurs months after the measurements are performed. This typically includes limited instrument drifts of a few percent. Missing records or records rejected by QC should be treated carefully when aggregating time series on daily, monthly, or yearly time scales, because of the strong solar radiation diurnal and seasonal cycles. Roesch et al. [2011] described aggregation methods that mitigate such problems.

This paper describes the uncertainty analysis of SW measurements using best available commercial technology as mandated by BSRN, under operating conditions that are realistic for long-term monitoring. This analysis applies to the measurements performed at the Payerne BSRN station and depends on their quality control and the set of instruments used for them. It can be used as an example of uncertainty analysis for cases where error sources are similar and when BSRN or equivalent guidelines are followed. The results from this analysis can be generalized to other stations performing the same measurements only if the same type of procedures is applied. Corrections are applied that derive from the quality analysis. In instances when a correction is applied, the uncertainty with and without the correction is given, allowing the reader to estimate the size of the uncertainty reduction resulting from the correction. The analysis focuses on $1 \mathrm{~min}$ measurement records obtained from averaging the voltage raw data from thermopile-based instruments sampled at $1 \mathrm{~Hz}$ frequency (see section 2.1). While the analysis considers usual uncertainty sources as described by manufacturers in specifications of their instruments, it also tries to evaluate the uncertainty contributions from other perturbations, such as soiling. The evaluation of the uncertainty is done in two steps: First, we combine the uncertainties affecting the individual elements of the measurement equation used for inferring solar irradiance from raw data-i.e., voltages-provided by the thermopile radiometers 
Table 1. List of Reference Instruments Used During the Intercomparison ${ }^{\mathrm{a}}$

\begin{tabular}{|c|c|c|c|c|c|}
\hline & \multirow[b]{2}{*}{ Instrument } & \multirow[b]{2}{*}{ Serial \# } & \multicolumn{2}{|r|}{ Calibration } & \multirow[b]{2}{*}{ Expanded Uncertainty on Sensitivity } \\
\hline & & & Period & Sensitivity & \\
\hline \multirow[t]{2}{*}{ Direct } & K\&Z CHP1 & 110740 & Nov 2011 K\&Z & $7.88 \mu \mathrm{V} /\left(\mathrm{W} \mathrm{m}^{-2}\right) \pm 0.09 \mu \mathrm{V} /\left(\mathrm{W} \mathrm{m}^{-2}\right)$ & $0.11 \mu \mathrm{V} /\left(\mathrm{W} \mathrm{m}^{-2}\right)$ \\
\hline & PMOD/WRC PMO6 & 891002 & Sep/Oct 2011 PMOD/WRC & $135.39\left(\mathrm{~m}^{2} \times \Omega\right)^{-1} \pm 0.06\left(\mathrm{~m}^{2} \times \Omega\right)^{-1}$ & $0.54\left(\mathrm{~m}^{2} \times \Omega\right)^{-1}$ \\
\hline \multirow[t]{2}{*}{ Diffuse } & K\&Z CMP22 & 080001 & Sep 2011 PMOD/WRC & $8.74 \mu \mathrm{V} /\left(\mathrm{W} \mathrm{m}^{-2}\right) \pm 0.06 \mu \mathrm{V} /\left(\mathrm{W} \mathrm{m}^{-2}\right)$ & $0.09 \mu \mathrm{V} /\left(\mathrm{W} \mathrm{m}^{-2}\right)$ \\
\hline & $\mathrm{K} \& Z \mathrm{CM} 21$ & 061653 & Sep 2011 PMOD/WRC & $11.83 \mu \mathrm{V} /\left(\mathrm{W} \mathrm{m}^{-2}\right) \pm 0.16 \mu \mathrm{V} /\left(\mathrm{W} \mathrm{m}^{-2}\right)$ & $0.22 \mu \mathrm{V} /\left(\mathrm{W} \mathrm{m}^{-2}\right)$ \\
\hline \multirow[t]{3}{*}{ Global } & K\&Z CMP22 & 080002 & $2008 \mathrm{~K} \& \mathrm{Z}$ & $9.40 \mu \mathrm{V} /\left(\mathrm{W} \mathrm{m}^{-2}\right) \pm 0.10 \mu \mathrm{V} /\left(\mathrm{W} \mathrm{m}^{-2}\right)$ & $0.13 \mu \mathrm{V} /\left(\mathrm{W} \mathrm{m}^{-2}\right)$ \\
\hline & $\mathrm{K} \& Z \mathrm{CM} 21$ & 051436 & Nov 2010 MeteoSwiss & $10.52 \mu \mathrm{V} /\left(\mathrm{W} \mathrm{m}^{-2}\right) \pm 0.12 \mu \mathrm{V} /\left(\mathrm{W} \mathrm{m}^{-2}\right)$ & $0.18 \mu \mathrm{V} /\left(\mathrm{W} \mathrm{m}^{-2}\right)$ \\
\hline & $\mathrm{K} \& Z \mathrm{CM} 21$ & 041306 & Nov 2010 MeteoSwiss & $10.73 \mu \mathrm{V} /\left(\mathrm{W} \mathrm{m}^{-2}\right) \pm 0.12 \mu \mathrm{V} /\left(\mathrm{W} \mathrm{m}^{-2}\right)$ & $0.18 \mu \mathrm{V} /\left(\mathrm{W} \mathrm{m}^{-2}\right)$ \\
\hline
\end{tabular}

\footnotetext{
${ }^{a}$ The calibration column gives the period of the calibration, the institution performing the calibration, and the value of the sensitivity with its expanded uncertainty as stated by the institution performing the calibration. The last column gives the expanded sensitivity uncertainty including the uncertainty from calibration and from other sources, which is computed in section 2.2.
}

(pyrheliometer, pyranometer, and shaded pyranometer) [Reda, 2011]. This first step follows the methodology of the "Guide to the expression of uncertainty in measurement" (GUM) [Joint Committee for Guides in Metrology, 2008]. Second, redundant measurements of the same parameters by multiple instruments are compared. They are also compared to a PMO6 absolute cavity radiometer (secondary standard) permanently operated at the Payerne BSRN station and eventually corrected so that compatibility with the PMO6 radiometer is improved (see section 3). The comparison between simultaneous measurements of a given parameter by multiple instruments is performed to verify that differences between instruments are compatible with the uncertainty determined in the first step. The PMO6 radiometer is calibrated by comparison with the reference absolute cavity radiometer $\mathrm{PMO}$, which is periodically calibrated against the WSG instruments constituting the World Radiometric Reference (WRR) [Fröhlich, 1977]. This chain of calibration with known uncertainty constitutes traceability to the WRR.

\section{Data and Method}

\subsection{Data}

Data analyzed here were collected at the BSRN station of Payerne, Switzerland $\left(46.815^{\circ} \mathrm{N}, 6.944^{\circ} \mathrm{E}\right.$, altitude $491 \mathrm{~m}$ ) from 15 June 2012 to 15 September 2013. This period of 15 months includes more than a full annual cycle, with two summers that are climatologically more prone to sunny episodes. During this period, different types of radiometers were compared to the reference BSRN instruments, which prompted the evaluation of the uncertainty of the reference instruments reported here. While this was an evaluation campaign conducted in the framework of the European Cooperation in Science and Technology (COST) Action ES1002 Weather Intelligence for Renewable Energies (WIRE) (www.wire1002.ch), we did not change the usual BSRN monitoring operational procedures applied at Payerne.

Ground radiation fluxes are monitored following the BSRN guidelines described by McArthur [2005] with the exception of the relaxed requirement on daily maintenance (section 1). These guidelines are designed to minimize measurement uncertainty, minimize the amount of missing data, and ensure traceability of BSRN data to radiometric reference standards.

The redundant measurements of SW GHI, DNI, and DfHI are sampled at $1 \mathrm{~Hz}$ frequency, and the corresponding $1 \mathrm{~min}$ statistics are recorded: average, standard deviation, minimum, and maximum. All data loggers are synchronized several times per hour to the same time server. This uncertainty analysis focuses on the 1 min averages. During the study period, the SW GHI measurements were carried out with three redundant pyranometers: two Kipp \& Zonen (K\&Z) CM21 and one K\&Z CMP22 (see Kipp \& Zonen [2013] for specifications), the DfHI measurements with one K\&Z CM21 and one K\&Z CMP22, and DNI was measured with a K\&Z CHP1 pyrheliometer [Kipp \& Zonen, 2008] and a PMO6 absolute cavity radiometer from the Physikalisch-Meteorologisches Observatorium Davos (PMOD)/World Radiation Center (WRC) (see Table 1). This is a standard configuration at Payerne BSRN. The pyranometers used for measuring DfHI are shaded by a disk affixed to an arm on a Sun tracker. The geometry of the shading system is set so that it covers an angle similar to the opening angle of the K\&Z pyrheliometer $\left(5^{\circ}\right)$, 
although because the shading disk is set perpendicular to the Sun beam while the pyranometer sensor is horizontal, and the sensor is of finite size as opposed to a point, the pyrheliometer angle is not exactly reproduced by the shading system.

The BSRN SW instruments feature expanded calibration uncertainties of 1-2\% (Table 1), except the PMO6 open absolute cavity radiometer, which has a calibration uncertainty on the order of $0.05 \%$. In addition, the latter is an extremely stable instrument: a calibration carried out in 2001 (10 years before the calibration currently in use) gave a sensitivity that is compatible with the current one, even considering the extremely small uncertainty. The calibration uncertainties quoted on the certificates are most of the time expanded uncertainties, which are obtained by multiplying the standard uncertainties by a coverage factor $k$ so that the expanded uncertainty includes the true value with a confidence level of $95 \%$. In case the uncertainty distribution is Gaussian, the coverage factor $k=\sim 2$. The small amplitude of the uncertainty quoted by the PMOD/WRC for the calibration of the PMO6 radiometer is due to the fact that this radiometer has a design nearly identical to the radiometers of the WSG defining the WRR. This uncertainty is actually only for the calibration by comparison to the WRR constituting the primary standards. The full calibration uncertainty should also include the expanded uncertainty of the WRR itself, which is estimated to be on the order of 0.3\% [Fröhlich, 1977].

As mentioned by Michalsky et al. [2011] and to the knowledge of the authors, Payerne is the only BSRN station where an open absolute cavity radiometer is operated for long-term measurements. This type of measurement is challenging because of the difficulty of dealing with precipitation and wind. The Payerne PMO6 radiometer is enclosed in a box with a protective curtain that closes when precipitation is detected, which allows operating it in parallel to the CHP1 pyrheliometer. However, the PMO6 is not suited for monitoring DNI when rapid changes are induced, for example, by clouds: it features a relatively long time constant. The thermal relaxation time constant of the PMO6 cavities is on the order of $10 \mathrm{~s}$, to which should be added the stabilization time of the heating control system depending on the efficiency of the electronics. At Payerne, it is operated with an open/close cycle of $120 \mathrm{~s}$ (self-calibration: cavity $60 \mathrm{~s}$ open with a $10 \mathrm{~s}$ measurement at the end of the period and $60 \mathrm{~s}$ closed with a $10 \mathrm{~s}$ measurement at the end of the period). This effectively results in one measurement every $2 \mathrm{~min}$.

Pyrheliometers and pyranometers have shorter time constants ( $<5 \mathrm{~s}$ for $95 \%$ response) and are better suited for measurements of rapidly changing irradiance. Therefore, the CHP1 provides the main DNI observation, but the PMO6 is used as reference to check the CHP1 performance when DNI is slowly changing, i.e., with no clouds at least in the direct beam path. In addition to the 1 min statistics data (see above), the average of the $1 \mathrm{~Hz}$ CHP1 measurements performed during the $10 \mathrm{~s}$ when the PMO6 is active (open and measuring) is also recorded for the comparison.

Given its calibration uncertainty of $\sim 0.05 \%$ and the long-term stability of its sensitivity, the PMO6 radiometer is used as a transfer standard traceable to the WRR with reproducibility better than $0.1 \%$ and an uncertainty due to the data acquisition electronics also better than $0.1 \%$ since the PMO6 data acquisition electronics is custom designed by PMOD/WRC. The dominant part of the uncertainty is thus the $0.3 \%$ expanded uncertainty quoted for the WRR, and the expanded uncertainty of the PMO6 measurements is considered to be $0.4 \%$ or lower.

\subsection{General Quality Analysis}

The main goal of the quality analysis for radiometers measuring SW irradiance at Payerne is to relate their measurements to those recorded by the PMO6 radiometer, so that they are traceable to the WRR through the PMO6. First, the CHP1 pyrheliometer is compared to the PMO6. Then, the pyranometers measuring $\mathrm{GHI}$ and $\mathrm{DFH}$ are compared to the $\mathrm{CHP} 1$ using the fact that $\mathrm{GHI}$ is the sum of the direct horizontal irradiance ( $\mathrm{DrHI})$ and $\mathrm{DfHI}$. The cosine of the solar zenith angle $\left(\cos \theta_{\mathrm{s}}\right)$ or equivalently the elevation angle sine $\left(\sin \xi_{\mathrm{s}}\right)$ is used to relate $\mathrm{DrHI}$ to the measured DNI.

\subsubsection{Pyrheliometer Quality Analysis}

CHP1 measurements are compared to PMO6 measurements selecting data when the apparent solar elevation angle $\xi_{s}$ is greater than $4^{\circ}$, when DNI is nonnegligible $\left(>30 \mathrm{~W} \mathrm{~m}^{-2}\right)$ and when it is slowly changing (the difference between two successive $1 \mathrm{~min}$ measurement is $<10 \mathrm{~W} \mathrm{~m}^{-2}$ for $\xi_{\mathrm{s}}>11.5^{\circ}$ and $<30 \mathrm{~W} \mathrm{~m}^{-2}$ for $11.5^{\circ} \geq \xi_{\mathrm{s}}>4^{\circ}$ ). The last condition on the rate of change is a limit on the differences 
between two consecutive 1 min measurements, but it is requested that the condition is true for at least $15 \mathrm{~min}$. These selection criteria are expressed as

1. $\xi_{\mathrm{s}}\left(t_{i}\right)>4^{\circ}$

2. $\mathrm{DNI}\left(t_{i}\right)>30 \mathrm{Wm}^{-2}$

3. $\max _{j \in[i, i+15 \min ]}\left|\operatorname{DNI}\left(t_{j+1}\right)-\operatorname{DNI}\left(t_{j}\right)\right|< \begin{cases}10 \mathrm{Wm}^{-2} \forall t_{j} \mid & \xi_{\mathrm{s}}\left(t_{i}\right)>11.5^{\circ} \\ 30 \mathrm{Wm}^{-2} \forall t_{j} \mid & 11.5^{\circ} \geq \xi_{s}\left(t_{i}\right)>4^{\circ}\end{cases}$

The criteria above typically select data measured when clouds do not obscure the Sun during at least 15 min. It is not the same as clear-sky data where no clouds are present in the sky, which is a very rare situation at Payerne. In order to verify the temporal evolution of the agreement between the CHP1 and PMO6 radiometers, the data sets are compared for selected days. These selected days must have at least 100 min satisfying the selection criteria described above, and the selected data should cover a DNI range (maximum-minimum) of at least $400 \mathrm{~W} \mathrm{~m}^{-2}$. For each day that fulfills the above criteria, a least squares linear regression analysis is performed comparing CHP1 to PMO6 measurements for the selected data. The linear regression slope, zero intercept, and root-mean-square deviation around the regression (standard deviation of the residuals) are checked to verify that they are compatible with the expected uncertainty of the PMO6 and more importantly of the CHP1.

The measurements of the CHP1 pyrheliometer are derived using $I_{c}=U / S_{C}$, where $I_{c}$ is the DNI in W m${ }^{-2}, U$ is the raw signal (voltage), and $S_{C}$ is the sensitivity here given in $\mu \mathrm{V} /\left(\mathrm{W} \mathrm{m}^{-2}\right)$. Assuming the uncertainties affecting $U$ and $S_{C}$ are uncorrelated, the standard uncertainty on $I_{C}$ can be derived with $\sqrt{c_{S}^{2} u_{S}^{2}+c_{U}^{2} u_{U}^{2}+u_{\mathrm{stat}}^{2}+\sum u_{\mathrm{op}}^{2}}$, where $c_{S}=\partial I_{C} / \partial S_{C}$ and $c_{U}=\partial I_{C} / \partial U$ are the sensitivity factors for $S_{C}$ and $U$, respectively, while $u_{S}$ and $u_{U}$ are the corresponding standard uncertainties [Reda, 2011]. The term $u_{\text {stat }}$ reflects a measurement uncertainty deduced from the width of the distribution obtained when sampling a stable quantity a large number of times with the measurement system. Here it is deduced from the standard deviation of the $1 \mathrm{~Hz}$ data measured during $1 \mathrm{~min}$ at times when DNI is slowly varying. The last term $u_{\mathrm{op}}$ represents the operational uncertainties. They are not explicitly listed in the measurement equation, but they can be thought of as either affecting $S_{C}$ or $U$. Known operational uncertainties are listed in section 2.3, and they are estimated from the data in section 3 . The combined standard uncertainty on $I_{C}$ is then

$$
u_{l}=\sqrt{\frac{u_{S}^{2} U^{2}}{S_{C}^{4}}+\frac{u_{U}^{2}}{S_{C}^{2}}+u_{\text {stat }}^{2}+\sum u_{\mathrm{op}}^{2}}
$$

According to its calibration certificate by PMOD/WRC, the CHP1 \#110740 has an expanded calibration uncertainty of $0.09 \mu \mathrm{V} /\left(\mathrm{W} \mathrm{m}^{-2}\right)$ or $1.14 \%$. This is converted to a standard uncertainty using the coverage factor. Several other sources of uncertainties should also be included in the combined uncertainty on $S_{C}$. The uncertainties from these sources are indicated by the manufacturer and include nonlinearity $<0.2 \%$, temperature dependence $<0.5 \%$, and aging $(<0.5 \%$ since the instrument was compared to a transfer standard during the intercomparison). The latter uncertainties are assumed to be rectangular distribution, and the standard uncertainties are obtained by dividing them by $\sqrt{3}$ [Reda, 2011]. They are combined with a quadratic sum with the calibration uncertainty to yield a standard uncertainty $u_{s}=0.72 \%$, which results in an expanded uncertainty for $S_{C}$ of $1.4 \%$ or $0.11 \mu \mathrm{V} /\left(\mathrm{W} \mathrm{m}^{-2}\right)$ - see Table 1 -assuming the major component, the calibration uncertainty, has a Gaussian distribution. The influence of the spectral response of the thermopile-based instruments used in this study is assumed to be negligible given their near-perfect response in the wavelength region including most of the solar irradiance energy [Kipp \& Zonen, 2008, 2013], and the fact that they are calibrated with the Sun as a source. In addition, the uncertainty $u_{U}$, affecting the measurement of the raw data voltage $U$, should also be accounted for, as well as the statistical and operational uncertainties (see equation (1)).

The uncertainty on the voltage measurement from the data acquisition and logging system is $0.1 \%$ of reading plus a negligible $0.01 \mu \mathrm{V}$ linked to the logger resolution and a nonproportional uncertainty (bias like) up to $40 \mu \mathrm{V}$. The data logging system was tested during 10 days with a forced zero voltage: a short circuit was created between the entries of one differential channel giving suspicious results when in use, while the other channels 
were measuring in the standard configuration. An offset of about $-30 \mu \mathrm{V}$ was found with a peak-to-peak amplitude of about $3 \mu \mathrm{V}$ depending on the measurement electronics temperature.

The combined standard uncertainty on $I_{c}$ is then $\sim 3.0 \mathrm{~W} \mathrm{~m}^{-2}$ for a DNI of $50 \mathrm{~W} \mathrm{~m}^{-2}$ and $8.3 \mathrm{~W} \mathrm{~m}^{-2}$ for a DNI of $1000 \mathrm{~W} \mathrm{~m}^{-2}$. These combined standard uncertainties correspond to expanded uncertainties of $5.8 \mathrm{~W} \mathrm{~m}^{-2}$ and $16.3 \mathrm{~W} \mathrm{~m}^{-2}$, respectively.

When comparing the CHP1 pyrheliometer to the PMO6 radiometer, the CHP1 uncertainty should be the dominant part. The agreement between the instruments estimated with least squares linear regression parameters for selected days (see above) should yield the following: a slope close to 1 with an expanded uncertainty corresponding to that for a large irradiance $(\sim 1.5 \%)$, a zero intercept close to zero with an uncertainty corresponding to that for a small irradiance $\left(\sim 6 \mathrm{~W} \mathrm{~m}^{-2}\right)$, and a root-mean-square deviation around the regression on the order of the standard uncertainty ( 3 to $8 \mathrm{~W} \mathrm{~m}^{-2}$ ).

\subsubsection{Pyranometer Quality Analysis for Global or Diffuse Irradiance}

GHI measurements are compared to DNI (from CHP1) after the CHP1 was compared to the PMO6 radiometer and its sensitivity factor checked (section 2.2.1). This comparison is similar to the continuous Sun and shade method for pyranometer calibration [International Organization for Standardization, 1993]: Measurements from a collocated shaded pyranometer (diffuse mode) are first compared to the global-mode pyranometer at times when the DNI intensity is negligible. Negligible DNI measurements are quality control validated pyrheliometer measurements that are less than $0.5 \mathrm{~W} \mathrm{~m}^{-2}$, i.e., compatible with zero. Since such $\mathrm{GHI}$ and $\mathrm{DfHI}$ measurements should be compatible within uncertainty, they are used to normalize DfHI to GHI measurements, and the slope of the linear regression is used for the normalization. Under the assumption that the normalization of DfHI to GHI performed with negligible DNI events is also valid for events with high DNI, DfHI measurements are then subtracted from GHI measurements for obtaining a global pyranometer estimate of DrHI. The global pyranometer estimates of DrHI are then compared to pyrheliometer estimates of DrHI obtained by multiplying DNI by $\cos \theta_{s}$.

Subtracting DfHI measurements from one pyranometer from $\mathrm{GHI}$ measurements from another pyranometer can be the source of increased uncertainty. Although, the DfHI measurements are normalized to the GHI measurements before subtraction, the instruments are in some cases of different types (CM21 versus CMP22) and have different characteristics, particularly thermal offsets. It is thus not trivial that the normalization performed with zero-DNI events holds for events with high stable DNI. To test the importance of such uncertainties, we repeated this analysis using all possible combinations: for each of the three pyranometers measuring GHI, we subtracted DfHI from one and from the other pyranometer measuring it. In addition, we performed this procedure either correcting for thermal offset or not correcting for these. For each of the three pyranometers measuring GHI, we thus obtained four results (subtraction of $\mathrm{DfH}$ from one or the other $\mathrm{DfHI}$ pyranometer, and with or without thermal offset correction). The uncertainties that are listed for the calibration correction in section 3.2.2 reflect the whole range of results obtained, and their small magnitude shows that such problem is not significant for the instruments used in this study.

This comparison uses the selection of events where DNI is slowly changing. Selection criteria identical to those described in section 2.2.1 are used, except that the analysis is not performed on individually selected days; the analysis was repeated either with a data set split in successive periods of several months or using the data set as a whole.

The data from the CM21 and CMP22 pyranometers are derived using $I_{X}=U_{X} / S_{X}-o$, where $I_{X}$ is $I_{G}$ for GHI or $I_{D}$ for $\mathrm{DfHI}$ in $\mathrm{W} \mathrm{m}^{-2}$ - the subscript $X$ stands for $G$ or $D$ for $\mathrm{GHI}$ or $\mathrm{DfHI}$, respectively- $U_{X}$ is the raw signal (voltage), $S_{X}$ is the sensitivity in $\mu \mathrm{V} /\left(\mathrm{W} \mathrm{m}^{-2}\right)$, and os is a correction for compensating an offset due to a thermal effect described in section 2.3.1. Reda [2011] used a different formula subtracting a thermal offset correction directly from the signal $U$, but the idea is the same.

The standard uncertainty for $I_{X}$ is derived as in section 2.2.1 with $\sqrt{c_{S}^{2} u_{S}^{2}+c_{U}^{2} u_{U}^{2}+c_{o s}^{2} u_{o s}^{2}+u_{\text {stat }}^{2}+\sum u_{\mathrm{op}}^{2}}$ using an additional term for $O s$, and as mentioned in section 2.2.1, the statistical and operational uncertainties $u_{\text {stat }}$ and $u_{\mathrm{op}}$. In addition, if the pyranometer is used for measuring $\mathrm{GHI}$, and the contribution from the direct solar beam is not negligible, a directional uncertainty should also be included in the operational uncertainties, 


\section{CAGU Journal of Geophysical Research: Atmospheres}

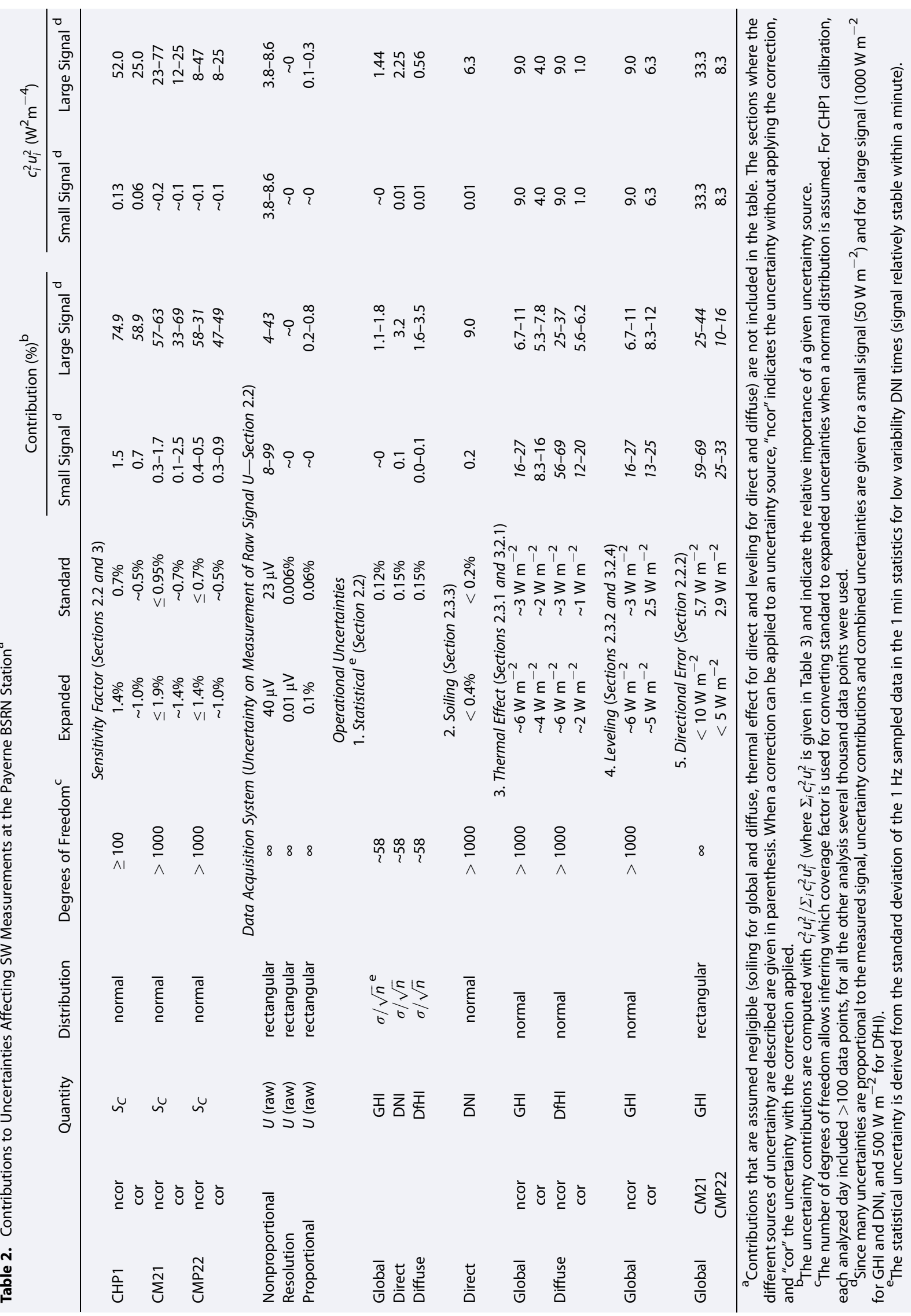




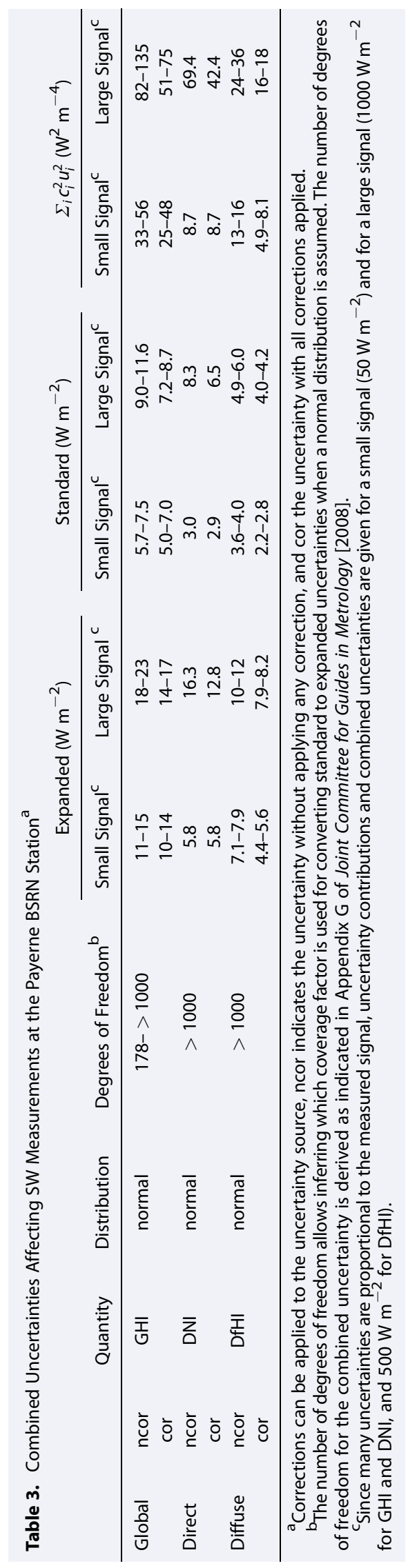

which is indicated by the manufacturer [Kipp \& Zonen, 2013] as $<5 \mathrm{~W} \mathrm{~m}^{-2}$ for CMP22 and $<10 \mathrm{~W} \mathrm{~m}^{-2}$ for CM21. This uncertainty source is also sometimes called cosine response or non-Lambertian uncertainty.

For the pyranometers, the calibration expanded uncertainty ranges from 0.06 to $0.16 \mu \mathrm{V} /\left(\mathrm{W} \mathrm{m}^{-2}\right)$ - see Table 1-or $0.67 \%$ to $1.35 \%$. Several other sources of uncertainties should also be included in the uncertainty on $S_{C}$. The uncertainty from these sources is indicated by the manufacturer and includes nonlinearity $(<0.2 \%)$, temperature dependence $(<0.5 \%$ for CMP 22 and $<1 \%$ for CM21), tilt error (negligible, because instruments are leveled), and aging $(<0.5 \%$ since the instruments are checked with a transfer standard during the intercomparison). As in section 2.2.1, the uncertainties are combined to yield a standard uncertainty on $S_{C}$ of $0.55 \%$ to $0.69 \%$ for CMP22 and of $0.87 \%$ to $0.95 \%$ for CM21, or an expanded uncertainty of $1.08 \%$ to $1.35 \%$ (CMP22), or $1.70 \%$ to $1.87 \%$ (CM21) -see Table 1 -assuming the major component of the calibration uncertainty has a Gaussian distribution.

The uncertainty on the voltage measurement from the data acquisition and logging system is again $0.1 \%$ of reading plus $0.01 \mu \mathrm{V}$ for logger resolution and the nonproportional uncertainty (not depending on the strength of the signal) of $40 \mu \mathrm{V}$ (see section 2.2.1). Taking into account the additional thermal offset uncertainty, the statistical uncertainty, and the operational uncertainties including the directional error for global irradiance, the combined $I_{X}$ standard uncertainty is then

$$
u_{l}=\sqrt{\frac{u_{S}^{2} U_{X}^{2}}{S_{X}^{4}}+\frac{u_{U}^{2}}{S_{X}^{2}}+u_{o s}^{2}+u_{\text {stat }}^{2}+\sum u_{o p}^{2}}
$$

This corresponds to an expanded uncertainty of 11 to $15 \mathrm{~W} \mathrm{~m}^{-2}$ (standard uncertainty: 5.7 to $7.5 \mathrm{~W} \mathrm{~m}^{-2}$ ) for a small global irradiance of $50 \mathrm{~W} \mathrm{~m}^{-2}$ and 18 to $23 \mathrm{~W} \mathrm{~m}^{-2}$ (standard uncertainty: 9.0 to $11.6 \mathrm{~W} \mathrm{~m}^{-2}$ ) for a large value of $1000 \mathrm{~W} \mathrm{~m}^{-2}$. For DfHl, this corresponds to an expanded uncertainty of 7.1 to $7.9 \mathrm{~W} \mathrm{~m}^{-2}$ (standard uncertainty: 3.6 to $4.0 \mathrm{~W} \mathrm{~m}^{-2}$ ) for a DfHI of $50 \mathrm{~W} \mathrm{~m}^{-2}$ and 10 to $12 \mathrm{~W} \mathrm{~m}^{-2}$ (standard uncertainty: 4.9 to $6.0 \mathrm{~W} \mathrm{~m}^{-2}$ ) for a large diffuse value of $500 \mathrm{~W} \mathrm{~m}^{-2}$ (see Table 2 for the contributing sources and Table 3 for the combined uncertainties).

\subsection{Operational Uncertainty Sources}

The uncertainties described above in section 2.2 are of two kinds: Those affecting the instrument sensitivity have been clearly identified by manufacturers. They are described and their limits are given in the instrument specifications. The other sources of uncertainties affecting operational measurements depend on the operational conditions and level of maintenance. They are typically soiling effects, leveling-induced errors, etc. (the latter for global SW 
irradiance, see section 2.3.2). These uncertainty sources have not been fully described in the uncertainty calculation explained in section 2.2. Also, some uncertainties considered in section 2.2 can be reduced by correcting errors within a quality analysis.

At Payerne, the quality analysis of SW irradiance compares the measurements by redundant instruments or combines different measurements (DrHI and $\mathrm{DfHI}$ for comparison with $\mathrm{GHI}$ ), and allows some reduction of the uncertainty. But it should be noted that in this case, spatio-temporal variability results in differences that are real but difficult to distinguish from errors, especially when the irradiance is highly variable (broken clouds).

Table 2 summarizes all the uncertainty sources analyzed in this work, including the ones described further. In addition, when corrections are possible as described in sections below, the uncertainties are given with and without the correction applied. The sections where the different uncertainty sources and corrections are described are given in the Table headings. Table 3 gives the resulting combined uncertainty, while Table 2 also indicates the relative importance of the contributions with respect to the sums indicated in Table 3. The assumed distributions are given, which are either normal (Gaussian) or rectangular. The latter is the type of distribution chosen when manufacturer specifications indicate that an uncertainty source has a contribution lower than a given limit. Tables 2 and 3 are described in more details and discussed in section 4.

In the following subsections and section 3, the signature of dominant operational uncertainties is sought in the statistics of the differences between multiple determinations of the same parameter for quantifying and eventually correcting these uncertainties. This is challenging because they are often on the same order and mask each other's effect.

\subsubsection{Thermal Effects}

Reference measurements performed at the Payerne BSRN station generally rely on a thermal response to irradiance being converted into an electrical signal, typically the voltage measured between the junctions of a thermopile. This makes such measurements sensitive to exogenous thermal effects. Some of these uncertainties are estimated by the manufacturers and often included in the data sheets, such as the temperature dependence of the radiometers and the zero offset $B$. However, pyranometers are affected by thermal offsets (also called zero offset $A$ ) that result from long-wave energy loss from the thermopile to the instrument domes and from the domes to the sky [Dutton et al., 2001; Ji and Tsay, 2000]. These effects can be mitigated by proper ventilation and heating of the dome, as is done at Payerne. They are thus influenced by the operation conditions (performance of the ventilation and heating system) and atmospheric conditions (cloud cover, temperature, and wind).

Pyrheliometers are relatively unaffected by such offsets since the opening angle is restricted and most of what the thermopile sees is the instrument collimator, whose temperature is relatively close to the thermopile temperature. It has been shown that pyrheliometers such as some versions of the Eppley Normal Incidence Pyrheliometer have uncertainties related to heating produced by the Sun on their front flange, which results in a heat flow through the instrument [Wilcox, 2008]. This produces effects that can be correlated with DNI and meteorological conditions affecting the cooling of the flange. Kipp \& Zonen $\mathrm{CH} 1$ and CHP1 pyrheliometers of the type used at Payerne BSRN are less affected, by construction, by such effects. The differences between the CHP1 and the PMO6 measurements of DNI do not seem correlated with the CHP1 temperature, the air temperature, or the wind speed $\left(r^{2}<0.03\right.$ for 31293 events).

The influence of thermal offsets on pyranometers is analyzed following the method suggested by Dutton et al. [2001]. Nighttime pyranometer data are used, and the deviations from zero are assumed to be mainly influenced by thermal offsets. Since thermal offsets are due to thermal infrared loss to the dome and then from the dome to the sky, Dutton et al. suggested that such an effect can be investigated using a collocated pyrgeometer with measurement of the dome temperature. In case that the assumptions are justified, the nighttime pyranometer data deviations from zero should be correlated with the long-wave net flux at the pyrgeometer thermopile ( $\left.L W_{\text {net }}\right)$ and the difference between the pyrgeometer dome and case temperature: $D C=\sigma\left(T_{\text {dome }}^{4}-T_{\text {case }}^{4}\right)$. The thermal behavior of the pyranometer and the pyrgeometer is expected to be similar enough so that the offsets can be expressed as os $=b_{0}+b_{1} L W_{\text {net }}+b_{2} D C$, where os is the thermal offset in $\mathrm{W} \mathrm{m}^{-2}, T_{\text {dome }}$ and $T_{\text {case }}$ are the pyrgeometer dome and case temperature, respectively, $\sigma$ is the StefanBoltzmann constant, and $b_{x}$ are regression coefficients [Dutton et al., 2001]. 


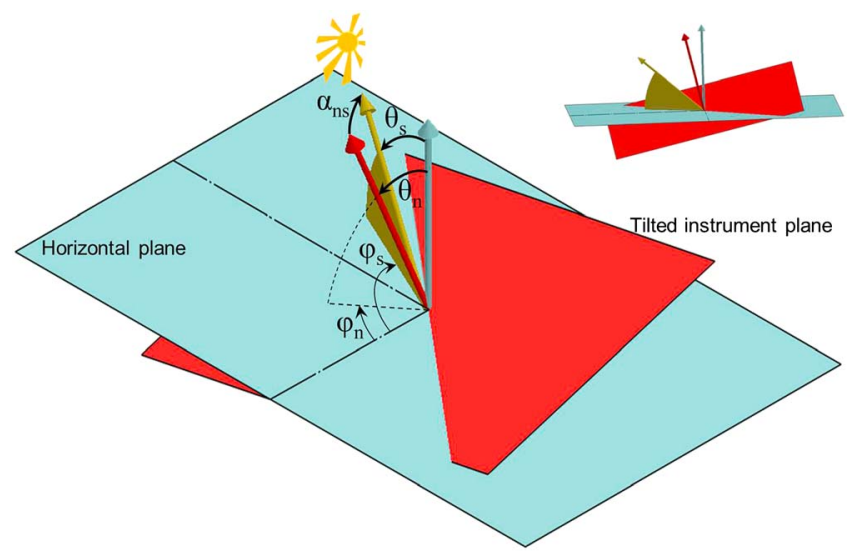

Figure 1. Schematics of the angles involved in the derivation of the $\mathrm{GHI}$ error resulting from an error in the leveling of a pyranometer. The blue plane is horizontal with its normal unit vector (blue arrow) at the zenith. The red plane includes the thermopile of the tilted instrument and its normal unit vector $\hat{n}$ is the red arrow. The yellow arrow represents the unit vector pointing in the direction of the Sun $\hat{s}$ (the Sun elevation angle is shown in solid yellow). The polar angles of the instrument plane normal vector and Sun vector are labeled as $\left(\theta_{n}, \varphi_{n}\right)$ and $\left(\theta_{s}, \varphi_{s}\right)$ respectively. The angle between these two vectors is $\alpha_{\mathrm{ns}}$.

horizontally leveled instrument should be used for operational measurements of GHI. In reality, an uncertainty also affects the leveling of the instrument and it results in an error (hereafter called levelinginduced error) which should not be confused with the abovementioned tilt error or the directional error.

In case that the measurement of $\mathrm{GHI}$ is not performed with a perfectly leveled pyranometer, an error will occur on the DNI contribution since it will not be projected onto a horizontal surface and thus not really equal to DrHI. Leveling-induced errors affecting DfHI are assumed negligible if the imprecision in leveling is small, because the diffuse component is relatively isotropic in the upper hemisphere, except for limb brightening of the horizon. The latter is expected to have a limited influence due to the cosine weighting of the angle of incidence onto the horizontal detector for horizon-like elevations. At sunset and sunrise though, limb brightening influence may be significant.

In order to reduce such an error, pyranometers include a high-accuracy bubble level to position the instrument as horizontally as possible. Typically, the residual zenith angle of the normal to the thermopile should be reduced to better than a few tenths of a degree [Kipp \& Zonen, 2013].

Simple trigonometry allows estimating the leveling-induced error if the error in the leveling of the pyranometer is known. With a leveling error described by the angles $\left(\theta_{n}, \varphi_{n}\right)$ as defined in Figure 1, the leveling-induced error is the result from projecting DNI on the instrument plane instead of projecting it on the horizontal plane. While the theoretical $\mathrm{DrHI}$ is obtained using $\mathrm{DNI} \cos \theta_{\mathrm{s}}$, the projection of DNI on the instrument plane is actually DNI $\cos \alpha_{\mathrm{ns}}$. Thus, the error is

$$
\begin{aligned}
\operatorname{err}_{\text {levl }}= & \operatorname{DNI}\left(\cos \alpha_{\mathrm{ns}}-\cos \theta_{\mathrm{s}}\right) \\
& \cos \alpha_{\mathrm{ns}}=\hat{n} \cdot \hat{\mathrm{s}}
\end{aligned}
$$

Using the following definition for $\hat{n}$ and $\hat{s}$

$$
\begin{array}{ccc}
n_{1}=\sin \theta_{n} \cos \varphi_{n} & n_{2}=\sin \theta_{n} \sin \varphi_{n} & n_{1}=\cos \theta_{n} \\
s_{1}=\sin \theta_{s} \cos \varphi_{s} & s_{1}=\sin \theta_{s} \sin \varphi_{s} & s_{1}=\cos \theta_{s}
\end{array}
$$

One obtains

$$
\begin{aligned}
\frac{\text { err }_{\text {levl }}}{\mathrm{DNI}} & =\sin \theta_{n} \cos \varphi_{n} \sin \theta_{s} \cos \varphi_{s} \\
& +\sin \theta_{n} \sin \varphi_{n} \sin \theta_{s} \sin \varphi_{s} \\
& +\cos \theta_{s}\left(\cos \theta_{n}-1\right)
\end{aligned}
$$


Long et al. [2010] also derived a formula for estimating this error, which similarly assumes that the diffuse SW component is virtually the same for the horizontal and tilted detectors for "modest tilts." They propose an iterative fitting procedure using a power law equation with the cosine of the solar zenith angle as the independent variable to determine the instrument offset from horizontal.

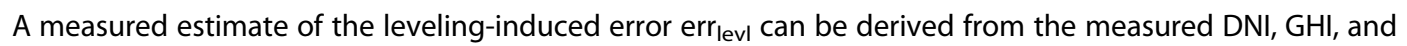
$\mathrm{DfHI}$, such as available at BSRN stations. In principle, err levl $=\mathrm{GHI}_{\mathrm{o}}-\mathrm{DfHI}_{\mathrm{o}}-\mathrm{DNI}_{\mathrm{o}} \cos \theta_{\mathrm{s}}$, where $\mathrm{GHI}_{\mathrm{o}}, \mathrm{DfHI}_{\mathrm{o}}$, and $\mathrm{DNI}_{\mathrm{O}}$ are the observed values of $\mathrm{GHI}, \mathrm{DfHI}$, and $\mathrm{DNI}$, respectively. In reality, various other uncertainties also contaminate these quantities in addition to the imprecision in leveling. Typically, such uncertainties include directional uncertainty, calibration uncertainty, pyranometer thermal offsets, effects of soiling, and, possibly, spatio-temporal variability if some distance separates the pyranometers and the pyrheliometer. These uncertainties can be reduced by correcting them (e.g., thermal offset, see above), with good maintenance (soiling) or by selecting data with low spatio-temporal variability (e.g., clear-sky data). Calibration uncertainty can be reduced by verifying the sensitivity constants with respect to standards and eventually correcting them as described in sections 2.2 and 3.2.

\subsubsection{Soiling Errors}

Because of collimation, pyrheliometers are more affected by soiling than other types of radiometers. If the pyrheliometer window is not clean, some radiation is attenuated by scattering and absorption and is not collected by the sensor. However, the PMO6 is windowless and thus less influenced by soiling. (This windowless instrument is not cleaned, and as mentioned in section 2.1, the characteristics of this instrument did not change: sensitivities from calibrations conducted in 2001 and 2011 differed by less than 0.06\%.) During summer 2010 at Payerne, exceptional circumstances resulted in a lack of daily maintenance for about 45 days. The lack of maintenance was detected by QC with a measurement error by the pyrheliometer of about $4 \%$. In-depth quality analysis showed that the loss of transmission due to soiling increased relatively constantly during this period.

Michalsky et al. [1988] tested the effect of soiling on a rotating shadowband radiometer using a photodiode detector in the region of New York. Over a period of 2 months, they compared measurements between a regularly cleaned instrument collocated with another that was intentionally not cleaned. They did not see an effect that could be distinguished considering the measurement uncertainty. Rain occurred at regular interval (about 10 days) and could act as a cleaning agent if it was sufficiently intense. Also, because the diffuser in this case is flat, radiation scattered by dust on the sensor still has a significant chance to be collected by the photodiode, and the effect of soiling is anticipated to be less significant than for a pyrheliometer.

Myers et al. [2001] reported on a 2 years study on the differences between the 1 min readings directly before and after a radiometer cleaning at 25 sites in the U.S. ARM program. Both pyranometers and pyrheliometers were tested at every station, and the cleaning frequency was once every 2 weeks. A control site was cleaned every day. They deduced the effect of soiling from the measurements directly before and after the cleaning. The mean cleaning effect for the pyranometers was $0.94 \mathrm{~W} \mathrm{~m}^{-2}$, while the control pyranometer exhibited a mean effect of $0.34 \mathrm{~W} \mathrm{~m}^{-2}$. For pyrheliometers, the mean cleaning effect was $4.5 \mathrm{~W} \mathrm{~m}^{-2}$, while the control pyrheliometer exhibited a mean effect of $3.0 \mathrm{~W} \mathrm{~m}^{-2}$. Given other sources of uncertainties, the pyranometer effect is most likely not significant, while the pyrheliometer effect may have some significance.

Geuder and Quaschning [2006] also tested the effect of soiling on different types of sensors (pyrheliometers and rotating shadowband radiometers) in the south of Spain. They cleaned the radiometers after periods of varying length and deduced the effect in a manner similar to Myers et al. [2001]. They confirmed that the effect of the soiling was more pronounced on pyrheliometers than on rotating shadowband radiometers. On pyrheliometers, they observed effects up to $5 \%$ after 10 days and up to $10-15 \%$ after 30 days. For rotating shadowband radiometers the effect was generally below $5 \%$.

In summary, for regular cleaning, at least performed several times a week, the effect should be well below the percent level. For pyrheliometers, the lack of maintenance can generate a soiling on the order of $\sim 1 \%$ per 10 days. Geuder and Quaschning [2006] found a larger effect, but their study took place in an arid environment with significant mineral dust and infrequent rain. All the above conclusions apply to regular soiling and not events such as soiling by birds. 


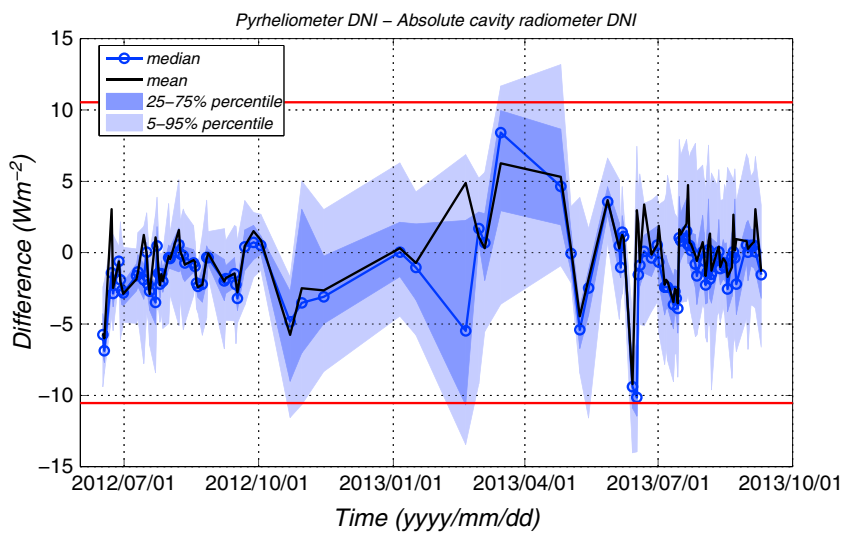

Figure 2. Evolution of the median and percentiles of the daily distribution of CHP1-PMO6 differences for slowly changing DNI (see text). The red lines are at $\pm 10.5 \mathrm{~W} \mathrm{~m}^{-2}$, which is $1.5 \%$ of the average value $\left(703 \mathrm{~W} \mathrm{~m}^{-2}\right)$ of the selected DNI data set analyzed here.

\section{Results}

\subsection{Direct Normal Irradiance}

The slowly varying irradiance selection described in section 2.2.1 results in 106 days with selected data from mid-June 2012 to mid-September 2013. The selection criteria produced a data set enriched in high-irradiance values: the average of DNI on the whole selected data set is $\sim 703 \mathrm{~W} \mathrm{~m}^{-2}$ (min: $30 \mathrm{~W} \mathrm{~m}^{-2}$, max: $988 \mathrm{~W} \mathrm{~m}^{-2}$ ). Figure 2 shows the extent of the daily distributions of the differences between the CHP1 and the PMO6 data (only for days with selected data).

The differences are mostly within $\pm 1.5 \%$ of the average of the selected DNI's $\left( \pm 10.5 \mathrm{~W} \mathrm{~m}^{-2}\right.$, red lines). During the months of summer, the distributions are even within $\pm 1 \%$, but from October to May, wider and more variable distributions are observed. These differences, revealed by QA, were investigated in more details. This situation was finally diagnosed as a problem of Sun tracking, and the Sun tracking system was inspected. A conjunction of factors made this problem more difficult to detect. First, the weather was very cloudy during an extended period from October 2012 to April 2013 at Payerne, and very few days could be selected for the slowly changing DNI quality analysis. Second, the problem was created by a four-quadrant photoelectric sensor designed to correct the alignment of the Sun tracker. The front window of the device suffered some loss of transparency over time that was not homogenous. This resulted in an erroneous correction that still had the Sun within the opening angle of the CHP1 and PMO6 radiometer, but not at the center. As a consequence, the uncertainty increased but the DNI measurements were not obviously wrong, which resulted in a long delay before the problem was identified and solved. This error depends on the intensity of the circumsolar radiation and cannot be corrected afterward.

Figure 3 shows the evolution of the fit parameters of a linear regression fit of CHP1 versus PMO6 measurements for the days with selected data. The slope and zero intercept are given with corresponding

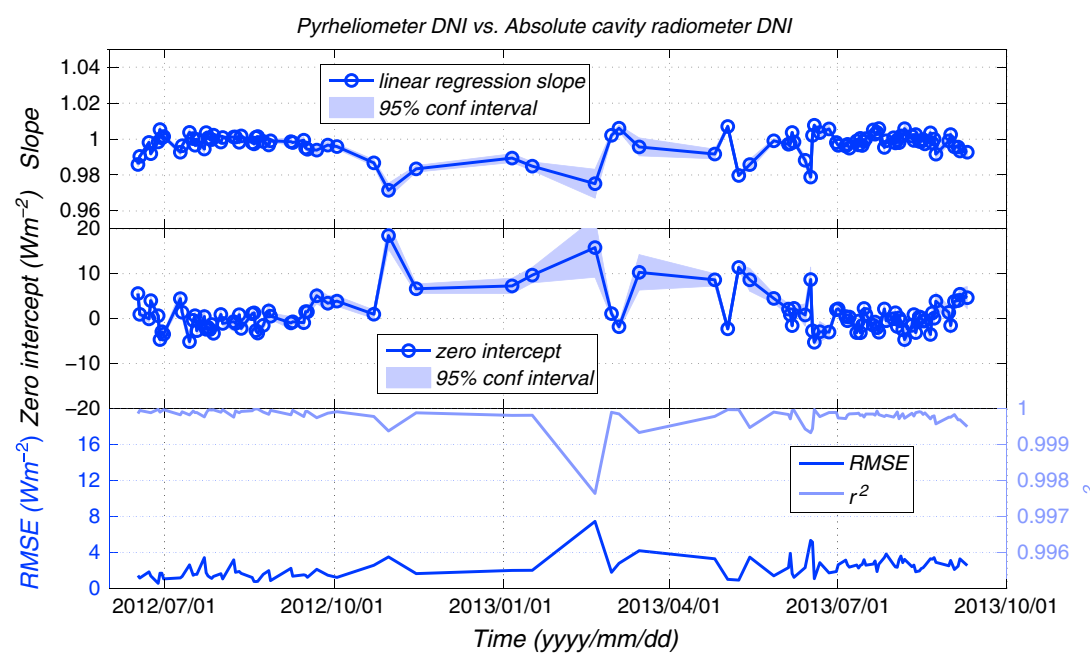

Figure 3. Evolution of linear regression fit parameters for $\mathrm{CHP} 1=a * \mathrm{PMO} 6+b$. The fit is performed for days with selected data. The slope $a$ and zero intercept $b$ are indicated with confidence intervals. The coefficient of determination $r^{2}$ and the RMSE are also given. 


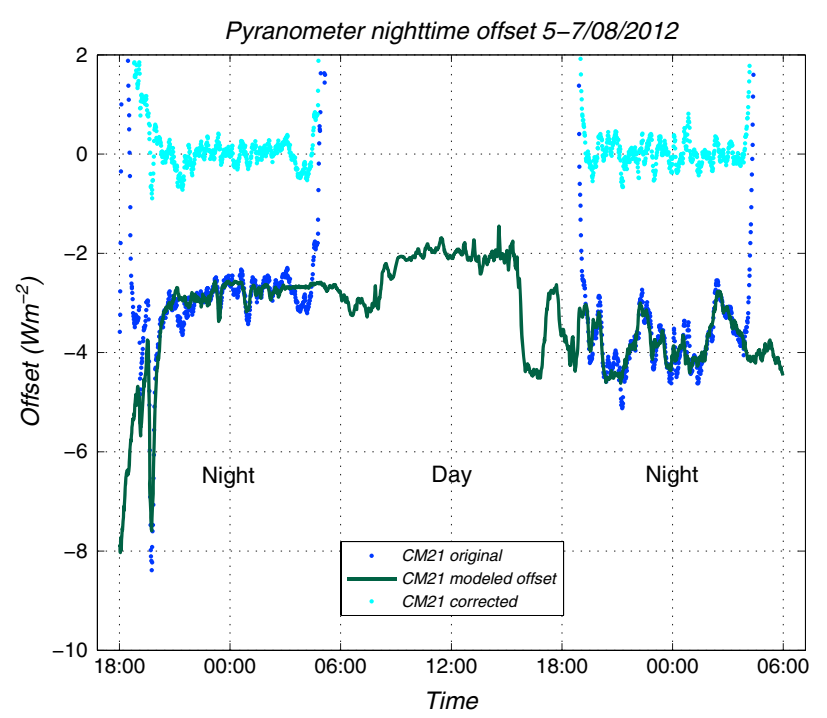

Figure 4. Example of thermal offset correction for 5-7 August 2012. Blue dots are the measured data of a Kipp \& Zonen CM21 pyranometer (S.N. 051436), the green line is the corresponding fitted model, and the cyan dots are the corresponding corrected values. confidence intervals, as well as the coefficient of determination $r^{2}$ and the RMSE with respect to the fit. As expected, the confidence intervals are relatively large during the October-May period mentioned above.

The criteria mentioned at the end of section 2.2.1 can then be checked: For most days, especially in summer, the zero intercept is within $\sim \pm 6 \mathrm{~W} \mathrm{~m}^{-2}$, thus compatible with zero. The difference of the slope from 1 is most of the time within $\pm 1.5 \%$, except again during winter ( 0.98). The RMSE with respect to the fit is, as expected, in the range of 3 to $8 \mathrm{~W} \mathrm{~m}^{-2}$.

\subsection{Global and Diffuse Horizontal Irradiance}

Some uncertainties result from error sources than can be partially corrected. These are the errors for which a prediction can be made or that exhibit some constancy (bias, multiplicative factor, etc.) For GHI and DfHI, these are essentially thermal offset, calibration error, and leveling-induced error (the latter is nonnegligible for GHI only). However, there are cross dependencies in the determination of errors. Typically, differences due to calibration error between a global and diffuse pyranometer can influence the determination of the leveling-induced error by the technique described in section 2.3.2. The order in which corrections are applied is thus not trivial. Quality analysis trials using different orders showed that a better consistency was obtained by applying first a thermal offset correction, then a calibration correction on GHI measurements, followed by a calibration correction on $\mathrm{DfHI}$, and finally a correction for the leveling-induced error on GHI.

Such an order is reasonable. Prediction of thermal offsets by the method of Dutton et al. [2001] primarily relies on offsets measured during the night as well as LW fluxes and temperatures measured on a pyrgeometer. They are thus not prone to be influenced by errors in calibration or leveling and should be determined first. On the other hand, the determination of leveling-induced errors relies on relating differences between a determination of the horizontal projection of DNI by a pyranometer and a pyrheliometer. This method is therefore vulnerable to offsets, calibration errors, or directional errors that can be interpreted as spurious leveling errors, and it should be applied only when the other errors are corrected as well as possible.

\subsubsection{Thermal Offset}

As described in section 2.3.1, differences from zero measured by pyranometers at night are used to fit the model $o s=b_{0}+b_{1} L W_{\text {net }}+b_{2} D C$ with $\left\{b_{i}\right\}$ as regression coefficients. Individual fits are performed for each night separately (defined as times when $\theta_{\mathrm{s}}>95^{\circ}$ ), and daytime estimates are obtained by interpolating the regression coefficients from one night to the next. Figure 4 shows an example of offset correction for pyranometer 051436 with original values (blue dots) as well as the corresponding model values (green line), and the corrected values (cyan dots).

The model agrees better with the data on the second night than the first where the conditions exhibited more variability. Some episodes with large offsets at the beginning of the first night (clear-sky conditions) were not well reproduced. However, the model agrees relatively well with the nighttime offsets with coefficient of determination $r^{2}=\sim 0.7$.

Figure 5 shows the histograms of offsets measured during night for four of the five pyranometers (the three global-mode pyranometers and one of the diffuse) operated at Payerne BSRN during the whole period considered. Both the original (blue histograms) and the corrected values (red), obtained by subtracting the result of the regression model, are indicated. The improvements for both the bias and the standard deviation are significant. In some cases, the distributions are multimodal. This is due to the dependence of the thermal 

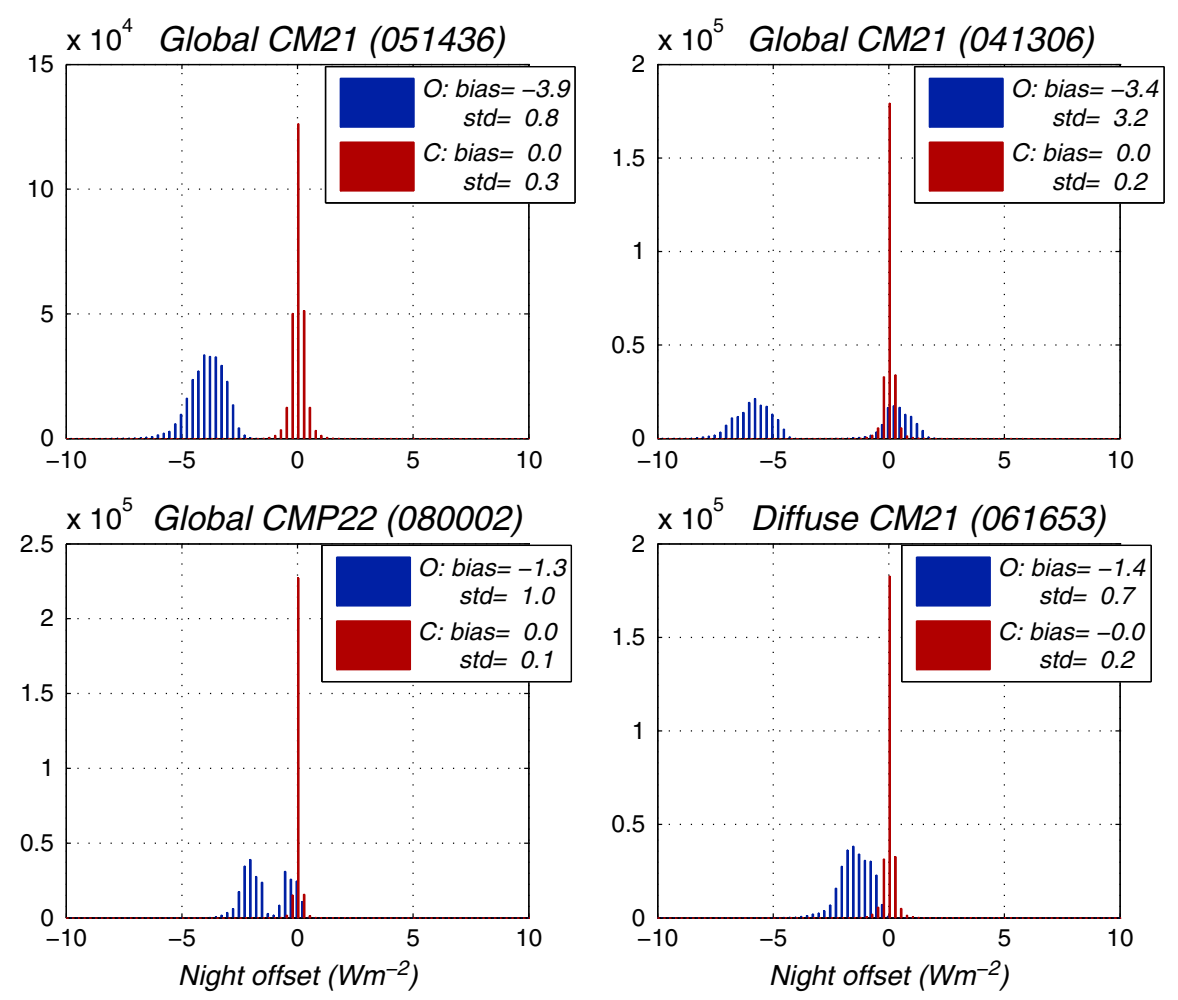

Figure 5. Distribution of nighttime offsets for original values $(O)$ and corrected values $(C)$ for four pyranometers operated at the Payerne BSRN station. The serial numbers given in parenthesis identify the instruments (see Table 1).

offset on the ventilation and heating of the instruments. Ventilation and slight heating help reduce errors resulting from soiling, dew, and frost. However, they depend on factors that are difficult to control, particularly the regularity of the air flow on the instrument or the relative humidity. The thermal offset correction exhibits significant variability, and if a correction is made, it should vary with time. For original values, the bias ranges between -1.3 and $-3.9 \mathrm{~W} \mathrm{~m}^{-2}$, and the standard deviation can reach a value greater than $3 \mathrm{~W} \mathrm{~m}^{-2}$, but for unimodal distribution it is $\sim 0.7 \mathrm{~W} \mathrm{~m}^{-2}$. The bias for the corrected value is negligible, and the standard deviations are significantly reduced to $\sim 0.2 \mathrm{~W} \mathrm{~m}^{-2}$.

Figure 6 shows the offset correction obtained by the regression model for the same pyranometers as in Figure 5. The daytime corrections are computed as described in section 2.3.1. Consequently, the daytime correction is computed assuming that the LW flux between the pyranometer thermopile and dome is correlated to $\mathrm{LW}_{\text {net }}$ and DC similarly for night and day. Under this assumption, Figure 6 shows that daytime and nighttime corrections are on the same order, but daytime corrections are in average less negative and they have significantly larger standard deviations, especially due to longer tails toward positive values. This can be explained by the fact that the difference between the ground temperature and the effective sky temperature has a larger range during day than during night, especially for clear-sky hot days.

The assumption that nighttime models for thermal offsets can be applied during days has some validity for CM21 and CMP22 pyranometers used in diffuse mode as it was demonstrated by Dutton et al. [2001] and Michalsky et al. [2003] through capping experiments. However, this assumption is more hazardous for pyranometers used in global mode. In this case, the thermopile is heated by direct Sun when it is present, and this may induce day-night differences in the correlation between the pyrgeometer and pyranometer thermopile-to-dome LW fluxes. The thermal offset in this case may be larger than the one predicted by the model.

Without corrections, the uncertainties due to thermal offset are 5-8 $\mathrm{W} \mathrm{m}^{-2}$. After the application of corrections, a residual uncertainty remains. It is composed of a nonreducible part of $\sim 1 \mathrm{~W} \mathrm{~m}^{-2}$ and a part that is proportional to the correction, probably up to the half of the correction for pyranometers in global mode. 

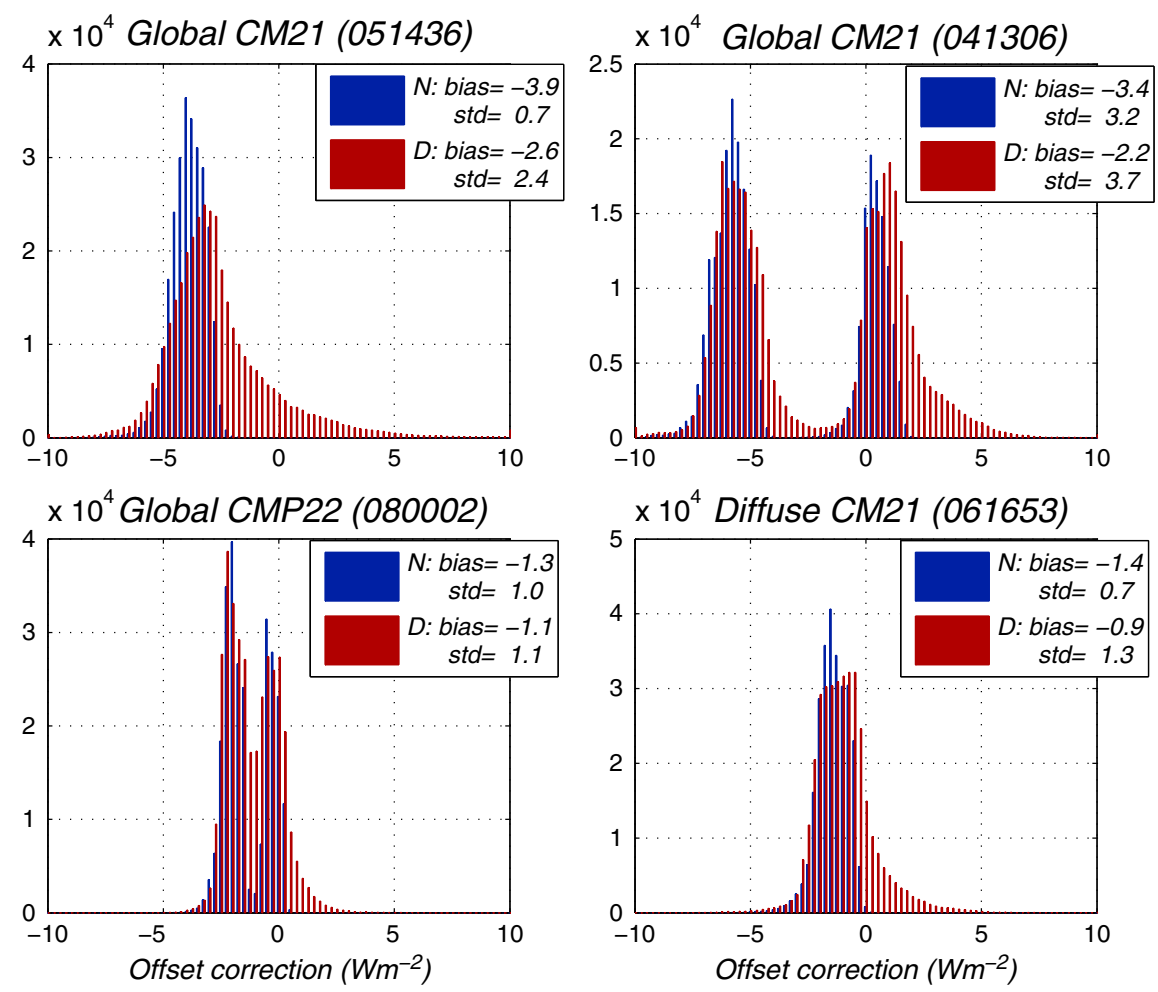

Figure 6. Nighttime and daytime corrections for thermal offset. The nighttime correction $(\mathrm{N})$ is the result of the regression model adjusted on each night, and the daytime correction (D) is the result of a model using interpolated regression coefficients from one night to the other. The serial numbers given in parenthesis identify the instruments (see Table 1).

This correction is useful for pyranometers in diffuse mode. For pyranometers used in global mode, more research should be conducted for investigating how well the correction behaves when the instrument receives the direct Sun beam. Here we decided to apply the correction in all cases, because of its efficiency at correcting large offsets when $L W_{\text {net }}$ is large.

\subsubsection{Calibration Error for Pyranometers Used in Global Mode}

As described in section 2.2, calibration corrections for pyranometers in global mode are computed by comparing DrHI estimates obtained by subtracting DfHI from GHI to DrHI estimates obtained by projection of CHP1 DNI on the horizontal plane, using only events with a slowly varying irradiance (see the beginning of section 2.2.2 for the method and Figure 7 for illustration). The slope of the least squares linear regression fit, as given in the legend of the figure, is used for correcting the calibration; here the sensitivity of the global CM21 would be multiplied by $\sim 1.01$. Since the raw data voltage is divided by the sensitivity, it would result in a decreased final value.

Figure 8 shows corrections computed for the data measured by the different pyranometers in global mode. The corrections displayed are the inverse of the slopes obtained by linear regression fits on data sets with various temporal aggregation so that corrections above or below 1 mean that we need to increase or reduce the original data, respectively. For example, the correction for CM21 041306 is between 0.984 and 0.989 , and multiplying this instrument's data by this correction factor lowers them by $1.1 \%$ to $1.6 \%$, meaning that the original data were actually too high. The true correction (the fit slope) acts on the sensitivity that is in the denominator of the measurement equations (see section 2). The corrections are indicated with error bars. The error bars are inferred by conducting multiple analyses: either one (S.N. 080001) or the other (S.N. 061653) diffuse-mode pyranometer is used for DfHI subtraction, and the thermal offset correction is either performed or not. This results in four different analyses. In addition, a statistical uncertainty component resulting from the spread of the data around the regression line is included, but it is a minor contribution with respect to the differences between the analyses. The error bar extends from the minimum to the maximum of the corrections resulting from the four analyses, also considering the statistical uncertainty component. In order to assess whether the inferred correction significantly changes with time, these analyses were 


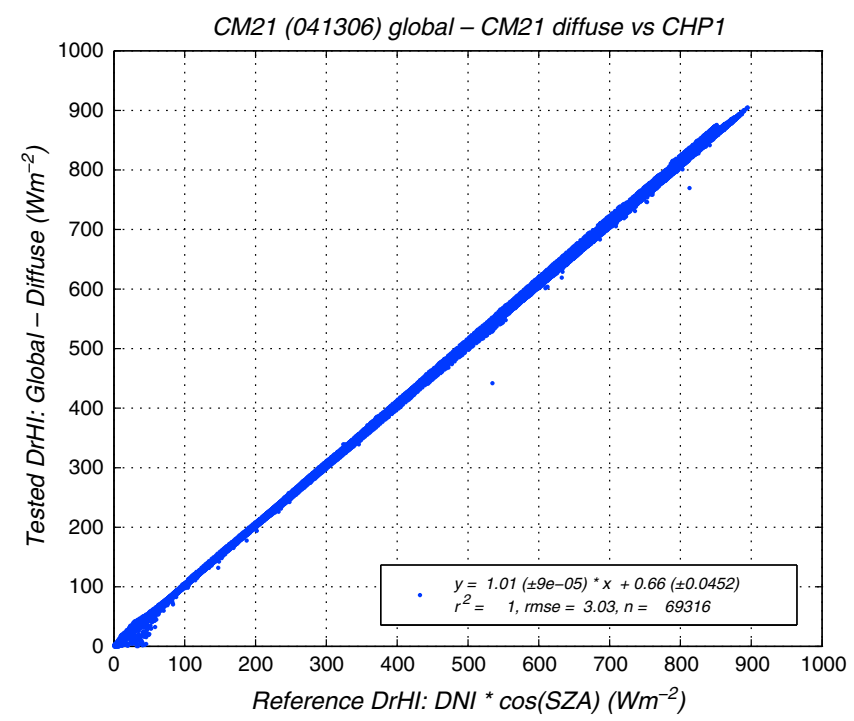

Figure 7. Comparison of pyrheliometer-derived DrHI with pyranometerderived $\mathrm{DrHI}(\mathrm{GHI}-\mathrm{DfHI})$. The results of a least squares linear regression fit are given in the legend.

data were consistently too high. As explained above, the analysis was repeated for all possible combinations of global/diffuse pyranometers, and with or without thermal corrections, which all produced consistent results (uncertainties in Figure 8 are all smaller than $0.3 \%$ ). The correction for one of the global CM21 is on the order of $0.5 \%$, while the correction for the other seems to be between $1.1 \%$ and $1.6 \%$. Both errors are within the expanded uncertainty range for the sensitivity and may be related to a small error in the sensitivity itself.

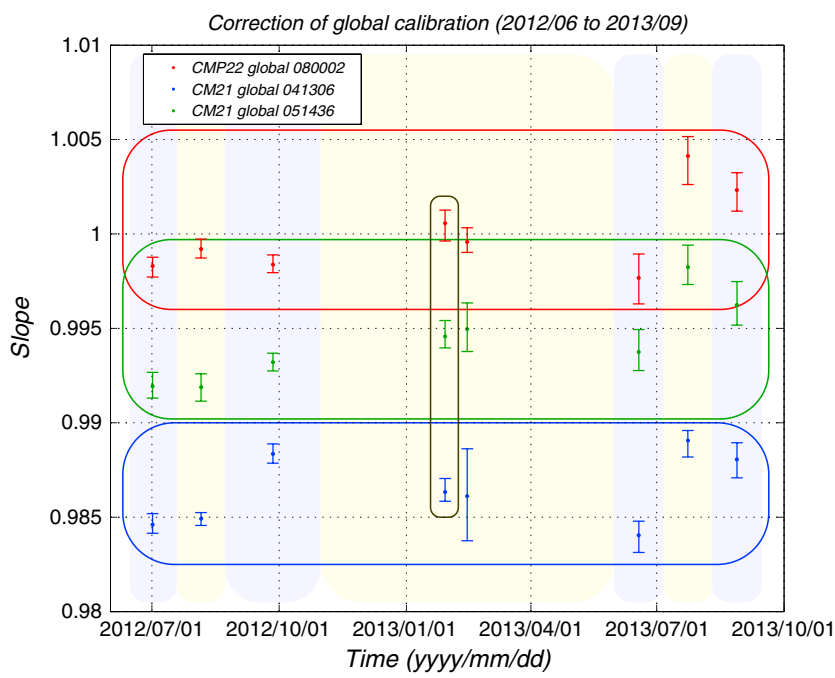

Figure 8. Corrections obtained by linear regression fit comparing pyranometer-derived DrHI (GHI - DfHI) with pyrheliometer-derived DrHI. Corrections computed for the three pyranometers used in global mode are shown. Data within the blue and green rectangles are the corrections for the two CM21, and the data within the red rectangle are for the CMP22. For testing the changes over time of the calibration correction, data are aggregated in seven time periods including similar number of events (between 6000 and 12000 selected events). The time periods are shown as colored background. The fit for the whole period is also given in the middle of the study period surrounded by a vertical brown rectangle. performed either using the whole data set (results enclosed within a brown rectangle) or for seven successive time periods (shown with colored background) resulting in selected data set of similar size (between 6000 and 12000 selected events).

The red, green, and blue rectangles enclose the fits performed for each of the global-mode pyranometers. All the rectangles are less than $1 \%$ wide, meaning that the calibration corrections are stable within $\pm 0.5 \%$. For the global CMP22, the calibration correction is not significant since all the computed values are well within $\pm 0.5 \%$ from 1. However, one of the CM21 has correction values of $0.983-0.990$. This is a difference larger than $1 \%$, and this correction is significant. The corrections for both CM21s indicate that the original Looking at the time evolution, there seem to be a gradual increase in the correction. But the patterns for all three pyranometers are similar, and this could be caused by another factor independent of the individual pyranometer sensitivities. In addition, the effect is small $(<1 \%)$ and is largely due to the correction for the last but one period (July-August 2013). Given the similarity of corrections obtained using different techniques or different periods, the chosen correction uses the average of the slopes obtained using both diffuse pyranometers with prior thermal offset correction during the whole period.

Dependence on solar elevation (directional uncertainty) was also investigated by splitting the whole data set in four subsets with respect to $\xi_{\mathrm{s}}: 4^{\circ}<\xi_{\mathrm{s}} \leq 20^{\circ}, 20^{\circ}<\xi_{\mathrm{s}} \leq 36^{\circ}$, $36^{\circ}<\xi_{\mathrm{s}} \leq 52^{\circ}$, and $52^{\circ}<\xi_{\mathrm{s}} \leq 68^{\circ}$. The analysis was repeated with the subsets, and all corrections found were also within a $1 \%$ band, except 


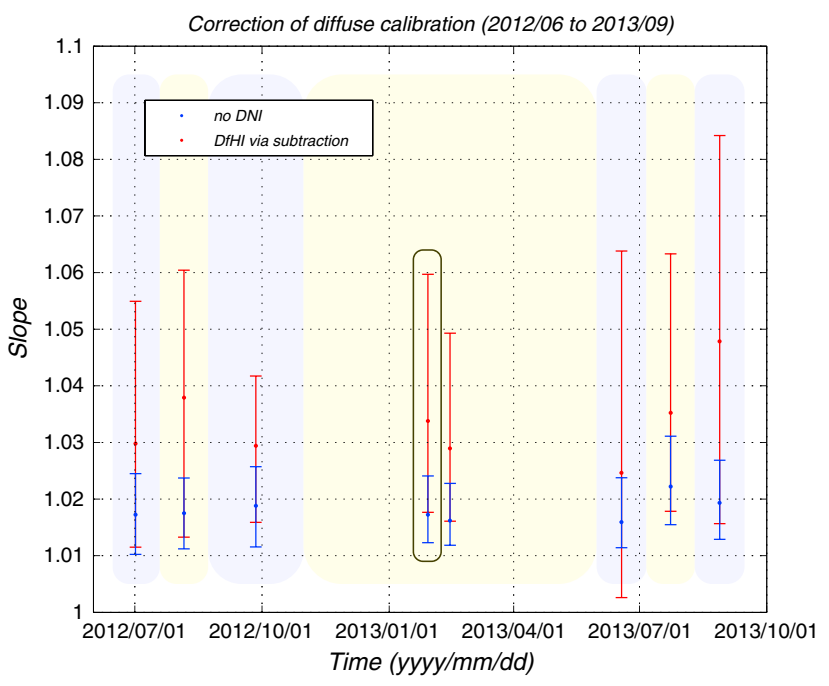

Figure 9. Corrections obtained by linear regression fits comparing DfHI with $\mathrm{GHI}$ at times when DNI is negligible (blue) and comparison of DfHI measured with a diffuse-mode pyranometer to $\mathrm{DfHI}$ derived from GHI - DrHI (red). Results are given for the CMP22 diffuse-mode pyranometer (S.N. 080001). Subsets using the same time aggregation as in Figure 8 are used, and the fit for the whole period is given in the middle of the study period surrounded by a brown rectangle. for one instrument/subset combination $\left(\mathrm{CM} 21051436\right.$ for $\left.4^{\circ}<\xi_{\mathrm{s}} \leq 20^{\circ}\right)$.

It seems possible to reduce the calibration uncertainty for global-mode pyranometers with such a method. Given the robustness of the corrections obtained by the various fits, one can assume a residual calibration uncertainty smaller than $1 \%$. However, since this method requires a determination of $\mathrm{DfHI}$, its uncertainty should also be considered, but it should be small. First, because events when DNI is negligible are used to normalize the diffuse pyranometer with respect to the global one. Second, because the DfHI uncertainty contribution to the global-mode pyranometer calibration uncertainty is reduced due to the fact that events selected for this analysis (slowly varying $\mathrm{DNI}$ ) have a relatively small diffuse contribution of $\mathrm{DfHI}$ to $\mathrm{GHI}$.

\subsubsection{Calibration Error for Pyranometers Used in Diffuse Mode}

Two methods are used for checking the calibration of diffuse-mode pyranometers: (1) comparison to globalmode pyranometer (after the calibration of the latter has been checked) for times when DNI is negligible during day; or (2) by comparison with DfHI computed by subtracting DrHI from GHI for times of slowly varying DNI, after the calibrations of the pyrheliometer and global-mode pyranometer have been checked. In the latter case, the analysis relies on $\mathrm{GHI}, \mathrm{DfHI}$, and DNI quality checked as valid, and the same slowly varying DNI selection as used for calibration checks of global-mode pyranometers.

The correction using the global-mode pyranometer at times when DNI is negligible relies on a data selection where all GHI, DfHI, and DNI have been quality checked as valid, and DNI is lower than $0.5 \mathrm{~W} \mathrm{~m}^{-2}$. For such events, DfHI is assumed to be equal to $\mathrm{GHI}$ within uncertainty. The influence of the shading disk, whose viewing angle amounts to $\sim 0.1 \%$ of the hemisphere solid angle, is assumed negligible since clouds are masking the Sun when DNI is negligible, and the corresponding region of the sky is not bright.

The negligible DNI technique exhibits more stable results than the slowly varying DNI technique (Figure 9) whose uncertainty seems significantly larger - the error bars are inferred similarly as for Figure 8 by considering all possible combinations of global/diffuse pyranometers, and with or without thermal corrections. The negligible DNI technique indicates that the CMP22 diffuse-mode pyranometer (S.N. 080001) original data were between $1.5 \%$ and $2 \%$ too low. Such a difference is surprising considering that we estimate the uncertainty on its sensitivity determined by PMOD/WRC to be slightly higher than $1 \%$. However, the method presented here compares the sensitivities of the diffuse pyranometers to the global pyranometers, and the uncertainties on the sensitivities of both instruments should be combined. It is also understandable that the slowly varying DNI technique has a much larger uncertainty because it combines two relatively large quantities ( $\mathrm{GHI}$ and $\mathrm{DrHI}$ ) to deduce $\mathrm{DfHI}$, which is usually significantly smaller. This technique also seems to produce corrections that are consistently larger than the negligible DNI technique and would indicate data that are significantly too low. This suggests that the uncertainty in GHI is very influential. It may also be related to the inhomogeneity of the diffuse irradiance in the vicinity of the Sun when DNI is high, especially when haze is present. Results for the diffuse-mode CM21 pyranometer are similar (not shown).

Given its robustness, the negligible DNI technique is chosen for diffuse pyranometer calibration correction. A residual uncertainty of $\sim 1.4 \%$ should be considered, given the fact that the uncertainty on the corrected $\mathrm{GHI}$ calibration should also be included in the uncertainty of this technique. 

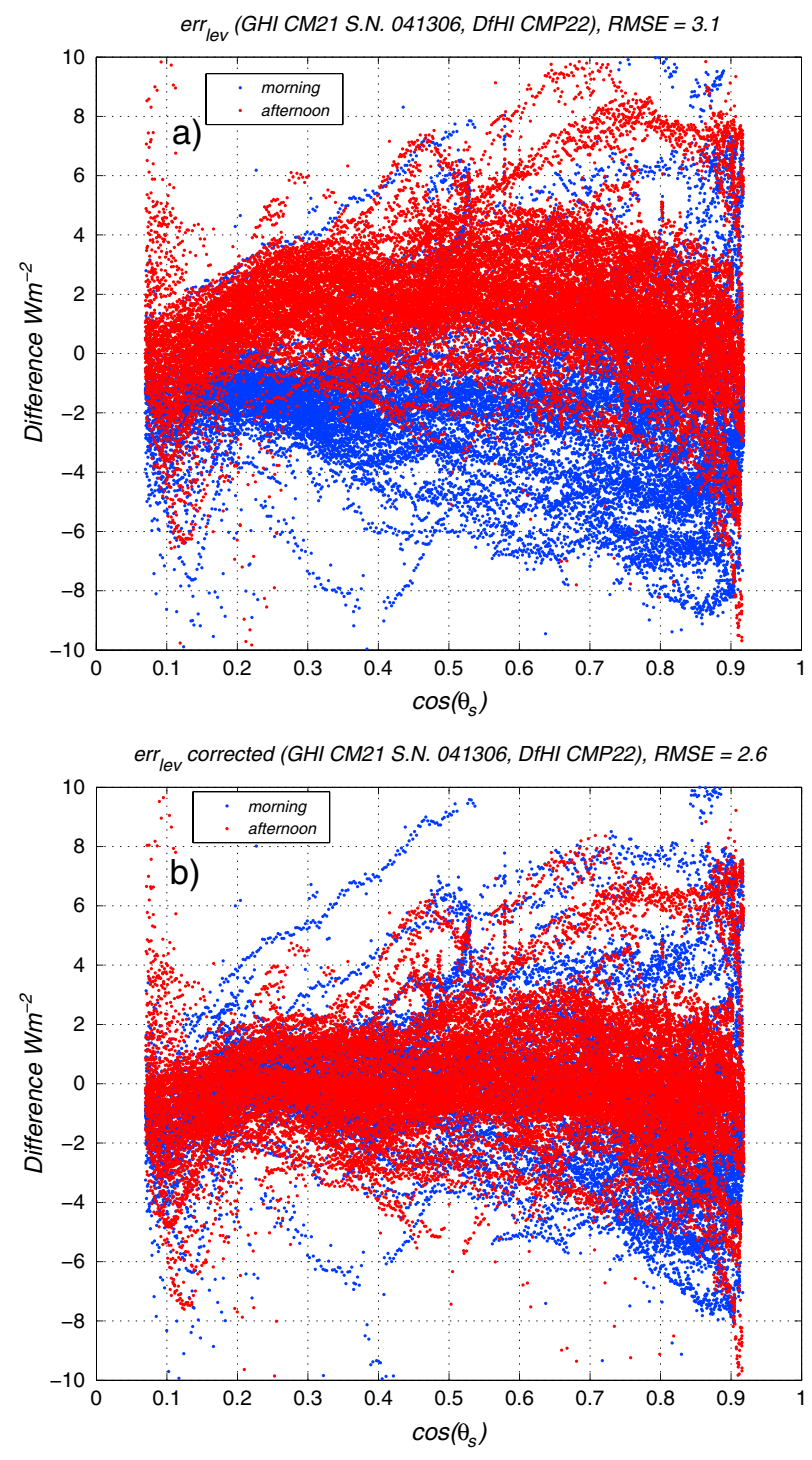

Figure 10. (a) Leveling-induced error err ${ }_{\text {levl }}$ obtained using measurements from the CHP1 pyrheliometer, one global CM21 (S.N. 041306) and the diffuse CMP22 pyranometer after thermal offset and calibration correction. Data with low-varying DNI are selected for $\varphi_{\mathrm{s}}$ less and greater than $180^{\circ}$ (morning and afternoon, blue and red dots); (b) Same as in Figure 10a but after correction of the DNI projection on the global pyranometer thermopile plane: instead of using $\cos \theta_{\mathrm{s}}$ for the projection, $\cos \alpha_{\mathrm{ns}}$ as defined in section 2.3.2 is used as multiplicative factor for DNI.

\subsubsection{Leveling-Induced Error}

Leveling-induced errors are estimated by fitting equation (3) with respect to the solar zenith and azimuth angles $\left(\theta_{\mathrm{s}}, \varphi_{\mathrm{s}}\right)$ with the tilt angles $\left(\theta_{n}, \varphi_{n}\right)$ left as fitting parameters (see section 2.3.2). The value of err levl is obtained with err $_{\text {levl }}=\mathrm{GHI}_{\mathrm{o}}-\mathrm{DfHI} \mathrm{o}_{\mathrm{o}}-\mathrm{DNI}_{\mathrm{o}} \cos \theta_{\mathrm{s}}$ using the observed value of $\mathrm{GHI}, \mathrm{DfHI}$, and DNI after thermal offset and calibration correction. Figure 10a shows err levl as function of $\cos \theta_{\mathrm{s}}$ for $\mathrm{GHI}$ measured by CM21 S.N. 041306. Data for $\varphi_{\mathrm{s}}$ lower or greater than $180^{\circ}$ (morning or afternoon) are shown with different colors.

The errors shown in Figure 10a are 3-4 times lower than the uncertainties, and their significance is questionable. However, it includes more than 59000 data points, which behave in a similar manner: Errors affecting morning measurements (blue dots) are generally negative, while those affecting afternoon measurements are generally positive (see Figure 10a). After the leveling correction (using angle $\alpha$ ns instead of $\theta$ s), the errors affecting morning and afternoon measurements are of the same magnitude and do not seem to exhibit consistently opposite sign (see Figure 10b). This improvement suggests that the correction is effective. This conclusion should be taken with caution because of the following confounding factors. First, systematic time shifts would produce effects that resemble an East-west tilt. Second, calibration errors between instruments measuring $\mathrm{GHI}, \mathrm{DNI}$, and $\mathrm{DfHI}$ would produce effects resembling a North-south tilt. Directional error (non-Lambertian response) of the pyranometer measuring $\mathrm{GHI}$ also complicates the analysis.

For investigating such confusing factors, the leveling-induced error analysis was repeated with all combinations of time shifts between $-2 \mathrm{~min}$ and $+1 \mathrm{~min}$ in $30 \mathrm{~s}$ steps, and calibration corrections using multiple periods or a single period (see sections 3.2.2 and 3.2.3). The best results (smallest tilt angles) were obtained with a time shift of $-30 \mathrm{~s}$, while the number of periods used for the calibration correction had no effect. A time shift of $-30 \mathrm{~s}$ makes sense because it allows computing $\left(\theta_{\mathrm{s}}, \varphi_{\mathrm{s}}\right)$ at the middle of the measurement integration period-Sun angles are computed with an algorithm derived from Reda and Afshin [2004].

Differences of $\sim 5 \mathrm{~W} \mathrm{~m}^{-2}$ between morning and afternoon data are observed. Such differences suggest an imprecision in leveling toward West since err ${ }_{\text {levl }}$ is lower during the morning than the afternoon. The fit 

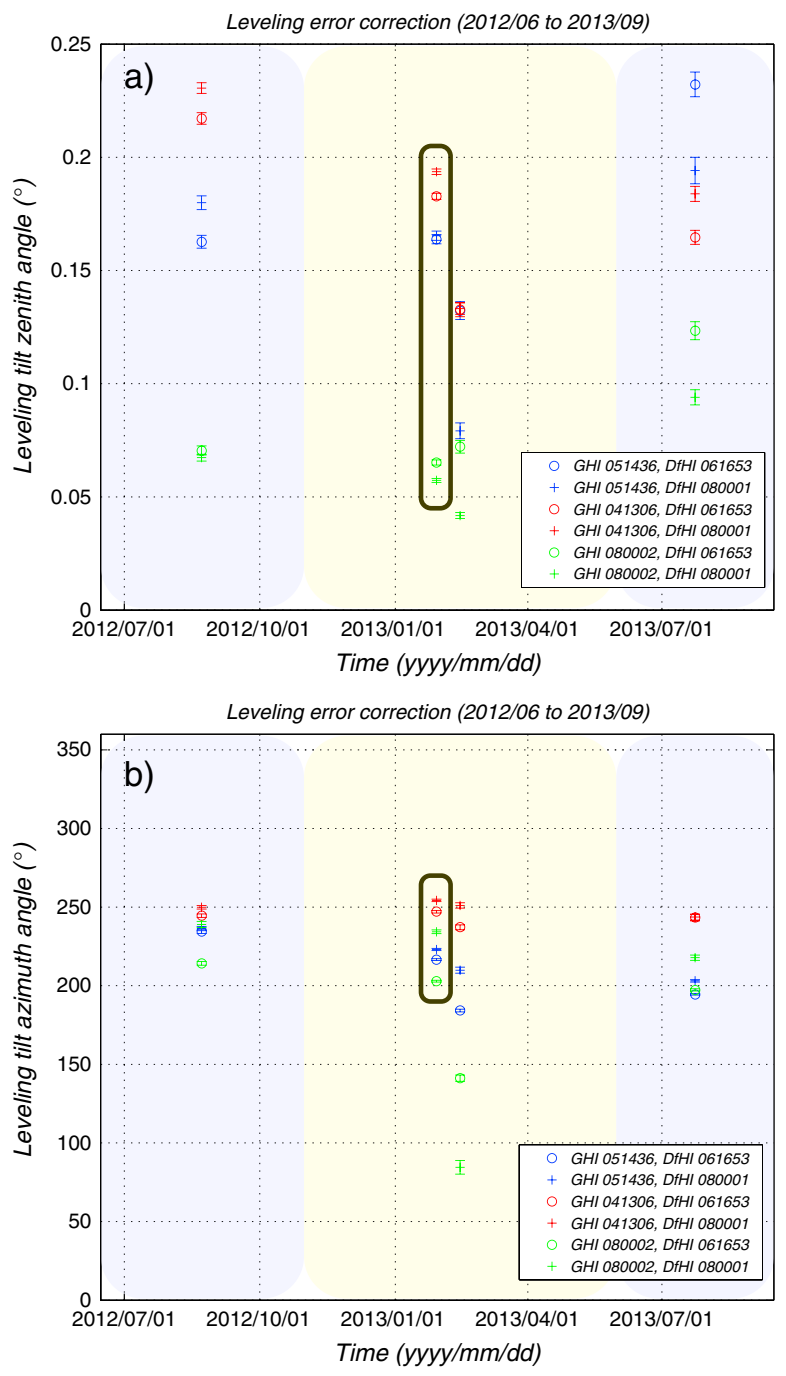

Figure 11. Fit results for (a) $\theta_{\mathbf{n}}$ and (b) $\varphi_{\mathbf{n}}$ for the three global-mode pyranometers (red, blue, and green, respectively) using either one or the other diffuse-mode pyranometer for DfHI subtraction (circle and crosses). Data sets are aggregated in three time periods (shown with colored background). It was not possible to use the same number of periods as for the calibration correction because large subsets were required to mitigate the effect of uncertainties (see text). The fit for the whole period is given in the middle of the study period surrounded by a brown rectangle. results for data in Figure 10 are $\theta_{\mathrm{n}}=0.17^{\circ}$ and $\varphi_{\mathrm{n}}=223^{\circ}$. Using the other diffuse pyranometer for DfHI subtraction results in similar angles. These results indicate North-West as the direction of the residual tilt.

Figure $10 \mathrm{~b}$ shows the same data as in Figure 10a, but instead of $\theta_{\mathrm{s}}$ for projection of $\mathrm{DNI}$, it considers the angle $\alpha_{\mathrm{ns}}$ (see section 2.3.2): i.e., diff $=\mathrm{GHI}_{\mathrm{o}}-$ $\mathrm{DfHI}_{\mathrm{o}}-\mathrm{DNI}_{\mathrm{o}} \cos \alpha_{\mathrm{ns}}$. Such a technique allows a reduction of the morning to afternoon difference in err levl, with the RMSE decreasing by $\sim 0.5$ out of $3 \mathrm{~W} \mathrm{~m}^{-2}$. This angle can also be used for correcting $\mathrm{GHI}_{\mathrm{O}}$, the global-mode pyranometermeasured value of $\mathrm{GHI}$

$$
\mathrm{GHI}=\left(\mathrm{GHI}_{\mathrm{o}}-\mathrm{DfH} \mathrm{I}_{\mathrm{o}}\right) \frac{\cos \theta_{\mathrm{s}}}{\cos \alpha_{\mathrm{ns}}}+\mathrm{DfH} \mathrm{I}_{\mathrm{o}}
$$

Large deviations going up or down by as much as $8 \mathrm{~W} \mathrm{~m}^{-2}$ in Figure 10 are most likely the result of soiling of the globalmode pyranometer. Since data corresponding to slowly varying irradiance are selected, DNI is likely to be strong. If a part of the pyranometer dome in the direct beam path is soiled, the direct beam intensity will be reduced for zenith and azimuth angles corresponding to the location of the soiling, and it will result in a signature as exhibited by the deviations mentioned here. Some systematic deviations are also apparent for $0.10<\cos \theta_{\mathrm{s}}<0.15$. These are probably due to a nonideal Lambertian response of the detector, and this can also have an influence on the analysis presented in this section.

Figure 11 shows the tilt angles $\theta_{\mathrm{n}}$ (Figure 11a) and $\varphi_{\mathrm{n}}$ (Figure 11b) for all the global-mode pyranometers resulting from all possible fits considering either the whole period or three successive periods and one or the other of the diffuse pyranometers for DfHI subtraction. The tilt angles resulting from the fit on the whole data set are similar for both global CM21 ( $\theta_{\mathrm{n}}$ between $0.15^{\circ}$ and $0.25^{\circ}$ except for the winter period), while for the CMP22, $\theta_{\mathrm{n}}$ values between $0.05^{\circ}$ and $0.10^{\circ}$ are found. The corresponding azimuth angles are generally oriented in the North-West direction $\left(\varphi_{\mathrm{n}}\right.$ between $200^{\circ}$ and $250^{\circ}$ ). Uncertainties on tilt angles are shown in Figure 11 , but they represent $95 \%$ confidence intervals computed by the fit procedure when considering only the data dispersion. These are clearly underestimated since they do not consider uncertainties affecting calibration, time shift, etc.

When splitting the data set into three periods, the fit results show a significant variability, especially for the global CM21s when comparing the extended winter period to the preceding and following summers. As mentioned in section 3.1, the accuracy of DNI was an issue during the extended winter period, which results 
in an increased calibration uncertainty, and a calibration error will induce an uncertainty in the determination of the leveling-induced error correction. In addition, the solar elevation angles reached in winter are limited to relatively small values where directional uncertainties can be more influential.

\section{Summary and Conclusions}

The uncertainty of broadband SW radiation monitoring has been determined for DNI, DfHI, and GHI measured at the Payerne BSRN station. Data obtained with independent radiometers of the best available commercial technology as mandated by BSRN were used for this analysis. It includes uncertainty sources that reflect realistic long-term operation conditions. In this study, 15 months of data are analyzed (15 June 2012-15 September 2013). While this study describes uncertainties reflecting the operational procedure applied at the Payerne BSRN station and that apply to these data only, it can be used as an example by other scientists monitoring SW irradiance following the BSRN guidelines for developing their own uncertainty analysis. Providing reliable uncertainty estimates is a significant community service that should be provided by site scientists with intimate knowledge of the procedures applied at their site for performing the monitoring.

The uncertainties were first derived from the measurement equations according to the GUM methodology. In the second step, redundant independent determinations of DNI, DfHI, and GHI were used to verify that the differences between redundant observations are compatible with the uncertainties. Third, the signature of some uncertainty sources was sought within the error statistics to find out if corrections can be applied and what their effect is.

Table 2 summarizes the uncertainty contributions determined in this study. The first three rows (subtitle "Sensitivity Factor") give uncertainties affecting the sensitivity of the instruments. These uncertainties are a combination of the calibration uncertainty as indicated by the certificate, and other sources such as nonlinearity and temperature dependence as indicated by the manufacturer. Since several instruments of types CM21 or CMP22 were used, the largest uncertainties are indicated when no corrections are applied (ncor). Correction methods based on comparisons with other radiometers, particularly the PMO6 transfer standard, are described in section 3; the estimated uncertainty after correction is also indicated (cor). The next three rows (subtitle "Data Acquisition System") are uncertainties affecting the measurement of the raw signal. The following rows (subtitle "Operational Uncertainties") are described here as operational uncertainties, including statistical uncertainties, soiling, thermal effects, leveling-induced, and directional uncertainties. Table 3 indicates the total combined uncertainties including all the sources described above.

The columns of Table 2 indicate the quantity names, type of assumed distributions, and number of degrees of freedom (NDF) followed by the expanded and standard uncertainties. The type of assumed distribution and the NDF allow determining which factor should be used for converting the standard uncertainties in expanded uncertainties [Joint Committee for Guides in Metrology, 2008]. The next two columns give a relative contribution in percent. They are based on the last two columns specifying the square of contributions as they are added to yield the quadratic sum of the contributions given in Table 3. The relative contributions are given in percent of the quadratic sum. Since many uncertainties are proportional to the measured signal, computations are made for a small signal $\left(50 \mathrm{~W} \mathrm{~m}^{-2}\right)$ and a large signal (1000 W m $\mathrm{m}^{-2}$ for DNI and GHI, and $500 \mathrm{~W} \mathrm{~m}^{-2}$ for DfHI).

Columns 3-5 of Table 3 are similar to the corresponding columns of Table 2. The NDF (column 5) is derived from the NDF of the contributions as indicated by the Joint Committee for Guides in Metrology [2008]. The last two columns (10-11) give the sum of the contributions from Table 2. The standard uncertainties (columns 8-9) are derived from these (square root), and the expanded uncertainties (columns 6-7) are derived from the standard ones. The factor for standard to expanded uncertainty conversion is computed assuming a normal distribution and using the NDF from column 3 as indicated by the Joint Committee for Guides in Metrology [2008].

The $\mathrm{GHI}$ and $\mathrm{DfHI}$ expanded uncertainties for large signals range from $1.8 \%$ to $2.4 \%$ without correction and are better than $1.7 \%$ with corrections. Therefore, they satisfy the BSRN uncertainty targets (2\%). For small signals however, the targets are not achieved ( 5 and $3 \mathrm{~W} \mathrm{~m}^{-2}$, respectively), and this is mainly because of the DAQ uncertainty, which results in an uncertainty of about $4 \mathrm{~W} \mathrm{~m}^{-2}$, and is the factor where the most important accuracy gain could be achieved in this case. Some DAQ systems have lower uncertainty, but a 
DAQ standardization was sought at MeteoSwiss for efficiency reasons. The problem is under investigation, and a solution with high-accuracy preamplification is sought for thermopile-based instruments.

The DNI uncertainty for large signal without correction is 1.6\%, 3 times higher than the BSRN uncertainty target. In this case also an accuracy gain could be achieved at the DAQ level. However, even without considering the DAQ uncertainty, the target is still exceeded by a factor of more than 2 . Even using an absolute cavity radiometer as transfer standard does not allow reducing the uncertainty of the instrument sensitivity below $\sim 1 \%$. This uncertainty is the main contribution to the combined uncertainty. The BSRN DNI accuracy target is probably not achievable with the current best available technology.

For clear-sky DNI larger than $700 \mathrm{~W} \mathrm{~m}^{-2}$, Michalsky et al. [2011] found expanded uncertainties of $\pm 0.7 \%$ for $\mathrm{K} \& \mathrm{Z} \mathrm{CH} 1$ pyrheliometers and between 0.7 and $1.4 \%$ for other types of pyrheliometers. Such estimates were derived by comparing a large number of pyrheliometers to three windowed absolute cavity radiometers, and not by summing up contributions from different uncertainty sources, as done here. In addition, they were more restrictive in their data selection. When using Michalsky et al's. technique for comparing the CHP1 pyrheliometer used in this study to the PMO6 radiometer, the lower and higher $95 \%$ uncertainty limits are $-8.6 \mathrm{~W} \mathrm{~m}^{-2}$ and $7.1 \mathrm{~W} \mathrm{~m}^{-2}$, respectively. Since all DNI for this selection are over $700 \mathrm{~W} \mathrm{~m}^{-2}$ and the average is $842 \mathrm{~W} \mathrm{~m}^{-2}$, these limits correspond to $-1.0 \%$ and $+0.8 \%$ and are slightly higher than the estimates by Michalsky et al. [2011], which could be due to a difference in DAQ uncertainty. This uncertainty of $\sim 1 \%$ corresponds to $10 \mathrm{~W} \mathrm{~m}^{-2}$ for a $1000 \mathrm{~W} \mathrm{~m}^{-2} \mathrm{DNI}$, which is slightly lower than the combined expanded uncertainty with corrections listed in Table 3.

In Table 2, the sources yielding the largest contribution to the combined uncertainty are given in italics. They depend on the type of parameter considered ( $\mathrm{GHI}, \mathrm{DNI}$, or $\mathrm{DfHI})$ and the strength of the signal, but the uncertainty affecting the sensitivity and the nonproportional DAQ uncertainty always yield important contributions, showing the usefulness of efforts for reducing them. For small signals, the sources whose estimates are given as absolute values (in $\mathrm{W} \mathrm{m}^{-2}$ ), and not relative to the signal, become important. In some cases (thermal effect), these uncertainty are truly nonproportional, but in other cases the rough limits given as uncertainty reflects the fact that the uncertainty is not well known. In this case, the uncertainty limits are often estimated under worst case scenario, and including several such sources in the combined uncertainty frequently leads to an overestimation of the uncertainty.

Finally, it should be emphasized that many uncertainty sources mentioned here are on the same order. In practice, it is difficult to differentiate the effect of uncertainties affecting the sensitivities, the measurement of the raw data itself and other uncertainties that were here characterized as "operational." It is only by conducting formal uncertainty analysis starting from the measurement equation and subsequently checking that the difference between redundant measurements are compatible with the uncertainties that confidence in these determination can be gained. Achieving such accuracy requires constant attention to all the uncertainty sources. Failure in controlling them quickly results in a strongly degraded accuracy, which is a constant challenge for high-accuracy long-term monitoring.

\section{Appendix A: Glossary}

DfHI Diffuse Horizontal Irradiance $\left(\mathrm{W} \mathrm{m}^{-2}\right)$; here defined experimentally as the shortwave irradiance of the upper hemisphere, excluding the irradiance within an opening angle of $5^{\circ}$ around the Sun, similar to the opening angle of modern pyrheliometers.

DNI Direct Normal Irradiance $\left(\mathrm{W} \mathrm{m}^{-2}\right)$; here defined experimentally as the shortwave irradiance within an opening angle of $5^{\circ}$ around the Sun, similar to the opening angle of modern pyrheliometers.

DrHI Direct Horizontal Irradiance $\left(\mathrm{W} \mathrm{m}^{-2}\right)$, which is equal to DNI multiplied by the cosine of the solar zenith angle.

$\mathrm{GHI}$ Global Horizontal Irradiance $\left(\mathrm{W} \mathrm{m}^{-2}\right)$, the total shortwave irradiance of the upper hemisphere which is theoretically equal to the sum of DrHI plus DfHI.

LW long-wave (irradiance), i.e., broadband wavelength range emitted by the Earth and the atmosphere especially the clouds and the water vapor in the thermal infrared. For thermopile-based instruments (pyrgeometer), the cutoff at shorter wavelength (near-IR) is around $4000 \mathrm{~nm}$. 
Solar azimuth angle $\left(\varphi_{\mathrm{s}}\right)$

Solar elevation angle $\left(\xi_{\mathrm{s}}\right)$ and solar zenith angle $\left(\theta_{\mathrm{s}}\right)$ defines the direction of the Sun on a horizontal plane. There are different conventions for this angle; we here follow the north-clockwise convention defining this angle between a line toward north and the projection of a line pointing toward the Sun on a horizontal plane. This convention states the angle is $90^{\circ}$ if the Sun is east and $180^{\circ}$ if the Sun is south.

two complementary angles (their sum equals $90^{\circ}$ ) defining how high the Sun is over the horizon (elevation) or how far it is from the zenith.

SW shortwave (irradiance), i.e., broadband wavelength range that includes most of the energy of solar radiation at the ground, from the ultraviolet (UV) to the near-IR. For thermopile-based instruments, depending on the instrument window (pyrheliometer) or dome (pyranometer), the longerwavelength cutoff (near-IR) is between $3000 \mathrm{~nm}$ and $4200 \mathrm{~nm}$, while at the other end of the range, window and dome materials such as fused silica or quartz transmit well the UV wavelengths reaching the Earth surface.

Uncertainty interval associated with the result of a measurement that characterizes the dispersion of the measured values around the true (unknown) value of the measured parameter that could reasonably be attributed to the measurement process.

1. Standard uncertainty is expressed as a standard deviation; in case it is assumed that the measured values have a Gaussian distribution, $\sim 68 \%$ of values are included in a \pm 1 standard uncertainty interval around the true value.

2. Expanded uncertainty is defining an interval that is expected to encompass a large fraction of the distribution of the measured values. This fraction is often set to $95 \%$, which in case of a Gaussian distribution of the measured values is about twice the standard uncertainty (coverage factor $\mathrm{k}=2$ ).

WRR World Radiometric Reference, the official main reference for SW radiometers.

WSG World Standard Group, an ensemble of absolute cavity radiometers used to define the WRR and maintained by the Physikalisch-Meteorologisches Observatorium Davos/World Radiation Center in Switzerland.

\section{Acknowledgments}

The data for this paper are available upon request from the corresponding author (laurent.vuilleumier(at)meteoswiss.ch). This work was triggered by an instrument performance evaluation conducted within the framework of COST Action ES1002 Weather Intelligence for Renewable Energies (WIRE) and the International Energy Agency Solar Heating and Cooling Programme Task 46. It would not have been possible without the dedication of the collaborators from the MeteoSwiss Measurement Technology Division. We also would like to thank the anonymous reviewers for their thoughtful comments.

\section{References}

Dutton, E. G., and C. N. Long with contributions by M. Wild, A. Ohmura, J. Groebner and A. Roesch (2012), Chapter 5: Long-term in-situ surface flux data products, in GEWEX Radiative Flux Assessment, vol. 1: Assessment, pp. 135-158, WCRP Report 19/2012, World Climate Research Programme, Geneva, Switzerland. [Available at http://www.wcrp-climate.org/documents/GEWEX\%20RFA-Volume\%201-report.pdf.]

Dutton, E. G., J. J. Michalsky, T. Stoffel, B. W. Forgan, J. Hickey, D. W. Nelson, T. L. Alberta, and I. Reda (2001), Measurement of broadband diffuse solar irradiance using current commercial instrumentation with a correction for thermal offset errors, J. Atmos. Oceanic Technol., 18(3), 297-314, doi:10.1175/1520-0426(2001)018<0297:MOBDSI > 2.0.CO;2.

Dutton, E. G., D. W. Nelson, R. S. Stone, D. Longenecker, G. Carbaugh, J. M. Harris, and J. Wendell (2006), Decadal variations in surface solar irradiance as observed in a globally remote network, J. Geophys. Res., 111, D19101, doi:10.1029/2005JD006901.

Fröhlich, C. (1977), World Radiometric Reference, in WMO/CIMO Final Report, pp. 97-110, World Meteorol. Organ., Geneva, Switzerland.

Geuder, N., and V. Quaschning (2006), Soiling of irradiation sensors and methods for soiling correction, Sol. Energy, 80(11), 1402-1409, doi:10.1016/j.solener.2006.06.001.

Gilgen, H., M. Wild, and A. Ohmura (1998), Means and trends of shortwave irradiance at the surface estimated from Global Energy Balance Archive data, J. Clim., 11(8), 2042-2061, doi:10.1175/1520-0442(1998)011<2042:MATOSI>2.0.CO;2.

International Organization for Standardization (1993), Calibration of a pyranometer using a pyrheliometer, ISO 9846, International Organisation for Standardization, Solar energy, Geneva, Switzerland.

Ji, Q., and S.-C. Tsay (2000), On the dome effect of Eppley pyrgeometers and pyranometers, Geophys. Res. Lett., 27(7), 971-974, doi:10.1029/ 1999GL011093.

Joint Committee for Guides in Metrology (2008), Evaluation of Measurement Data — Guide to the Expression of Uncertainty in Measurement, Bureau International des Poids et Mesures, Paris, France.

Kipp \& Zonen (2008), Instruction Manual - CHP1 Pyrheliometer. [Available at http://www.kippzonen.com/Download/202/CHP1-PyrheliometerManual, accessed 18/06/2014.]

Kipp \& Zonen (2013), Instruction Manual - CMP series Pyranometer - CMA series Albedometer. [Available at http://www.kippzonen.com/ Download/72/Manual-Pyranometer-CMP-series-English, accessed 18/06/2014.]

Long, C. N., and Y. Shi (2008), An automated quality assessment and control algorithm for surface radiation measurements, Open Atmos. Sci. J., 2, 23-37, doi:10.2174/1874282300802010023.

Long, C. N., A. Bucholtz, H. Jonsson, B. Schmid, A. M. Vogelmann, and J. Wood (2010), A method of correcting for tilt from horizontal in downwelling shortwave irradiance measurements on moving platforms, Open Atmos. Sci. J., 4, 78-87, doi:10.2174/1874282301004010078.

McArthur, L. J. B. (2005), Baseline Surface Radiation Network (BSRN) Operations Manual Version 2.1, WMO/TD-No. 1274, World Meteorol. Organ., Geneva, Switzerland. 
Michalsky, J. J., R. Perez, R. Stewart, B. A. LeBaron, and L. Harrison (1988), Design and development of a rotating shadowband radiometer solar radiation/daylight network, Sol. Energy, 41(6), 577-581, doi:10.1016/0038-092X(88)90060-6.

Michalsky, J. J., et al. (2003), Results from the first ARM diffuse horizontal shortwave irradiance comparison, J. Geophys. Res., 108(D3), 4108, doi:10.1029/2002JD002825.

Michalsky, J., et al. (2011), An extensive comparison of commercial pyrheliometers under a wide range of routine observing conditions, J. Atmos. Oceanic Technol., 28(6), 752-766, doi:10.1175/2010JTECHA1518.1.

Myers, D. R., R. Andreas, T. Stoffel, I. Reda, S. Wilcox, P. Gotseff, and B. Kay (2001), Radiometric Calibrations, Measurements, and Standards Development at NREL, National Renewable Energy Laboratory, Lakewood, Colo.

Ohmura, A., et al. (1998), Baseline Surface Radiation Network (BSRN/WCRP): New precision radiometry for climate research, Bull. Am. Meteorol. Soc., 79, 2115-2136, doi:10.1175/1520-0477(1998)079<2115:BSRNBW>2.0.CO;2.

Peppler, R. A., et al. (2008), An overview of ARM program climate research facility data quality assurance, Open Atmos. Sci. J., 2, 192-216, doi:10.2174/1874282300802010192.

Reda, I. (1996), Calibration of a Solar Absolute Cavity Radiometer With Traceability to the World Radiometric Reference, National Renewable Energy Laboratory, Golden, Colo.

Reda, I. (2011), Method to Calculate Uncertainties in Measuring Shortwave Solar Irradiance Using Thermopile and Semiconductor Solar Radiometers, National Renewable Energy Laboratory, Golden, Colo.

Reda, I., and A. Afshin (2004), Solar position algorithm for solar radiation applications, Sol. Energy, 76(5), 577-589, doi:10.1016/j.solener.2003.12.003.

Roesch, A., M. Wild, A. Ohmura, E. G. Dutton, C. N. Long, and T. Zhang (2011), Assessment of BSRN radiation records for the computation of monthly means, Atmos. Meas. Tech., 4(2), 339-354, doi:10.5194/amt-4-339-2011.

Wilcox, S. (2008), The effects of the thermal environment on the Eppley Normal Incidence Pyrheliometer, in Summary Report From the Tenth Session of the Baseline Surface Radiation Network (BSRN), De Bilt, The Netherlands, WCRP Informal Report N ${ }^{\circ} 11 / 2008$, World Climate Research Programme, Geneva, Switzerland.

Wild, M. (2012), Enlightening global dimming and brightening, Bull. Am. Meteorol. Soc., 93(1), 27-37, doi:10.1175/BAMS-D-11-00074.1. 